\title{
TREATMENT OF CIRRHOSIS OF THE LIVER BY A NUTRITIOUS DIET AND SUPPLEMENTS RICH IN VITAMIN B COMPLEX
}

\author{
By ARTHUR J. PATEK, JR. AND JOSEPH POST \\ (From the Research Service, First Division, Welfare Hospital, Department of Hospitals; and \\ the Department of Medicine, College of Physicians and Surgeons, Columbia \\ University, New York City)
}

(Received for publication April 24, 1941)

The present paper reports observations on 54 patients with cirrhosis of the liver who were treated by means of a highly nutritious diet together with vitamin $\mathrm{B}$ concentrates. The basis for this treatment rests on several clinical and experimental observations. It is known that the incidence of cirrhosis of the liver is high in certain countries where nutritional deficiencies are endemic $(1,2)$. Although malaria is blamed popularly for the high incidence of cirrhosis in these countries $(3,4)$, there is no direct evidence that malaria produces cirrhosis of the liver $(5,6)$. The association of cirrhosis and malaria suggests that the latter is a predisposing factor rather than a primary etiologic agent. The coincidence of enteric diseases with cirrhosis of the liver and with deficiency diseases may be explained similarly. In the western hemisphere cirrhosis of the liver, like beriberi and pellagra, is often associated with chronic alcoholism. Since "alcoholic" beriberi (7) and "alcoholic" pellagra (8) have been shown to be similar to the endemic beriberi and pellagra both in symptoms and response to therapy, it has been concluded that alcoholism merely predisposes to these nutritional deficiency diseases. It seemed possible that the correlation between alcoholism and cirrhosis of the liver might also be due to coexisting nutritional deficiency.

Experimental evidence to support this hypothesis has accumulated in recent years. It has been known that starvation renders the liver more vulnerable to injury by hepatotoxins (9). Lack of certain food factors contained in yeast are said to cause fatty changes in the liver (10) and impaired function (11). Recent studies by György (12) and by Rich (13) and their coworkers reveal that cirrhotic changes may possibly be produced in the rat and rabbit by feeding a diet deficient in unknown factors contained in yeast. It has also been shown that the feeding of excess fat (14) or of excess cystine (15) results in fibrotic changes in the liver. Other studies indicate a protective action against hepatotoxins by the feeding of yeast $(16,17)$ or of high protein diets $(18,19,20)$. It is possible that a balance of food factors may be essential to the integrity of a complex organ like the liver.

In a preliminary report on the treatment of 13 patients with alcoholic cirrhosis of the liver (21), it was noted that, in addition to signs of liver failure, there was evidence of specific malnutrition, notably of the vitamin B complex. These patients were fed a nutritious diet together with vitamin supplements. The improvement that followed treatment appeared to be outside chance expectations. However, since there is much variability in the degree of liver failure of different patients, and since these patients were observed for only one year, it seemed advisable to extend the program over a longer period of time. It was also important to compare their course with that of a similar group of hospitalized patients who had not received special dietary therapy.

CASE MATERIAL

The patients were obtained by transfer from municipal hospitals in New York City, and from the wards of private hospitals. Therefore, as an economic group they are composed of the underprivileged class. They may be considered "unselected" in regard to the stage of their liver disease. ${ }^{1}$ Since they were hospitalized because of liver failure, they represent a more advanced degree of liver incompetence than patients who are ambulatory, or who are being treated in outpatient clinics.

\footnotetext{
1 Excluded from this series are 2 patients who underwent splenectomy and omentopexy 7 and 6 years, respectively, before entering the Research Service.
} 
TABLE I

Clinical data on patients with cirrhosis of the liver

\begin{tabular}{|c|c|c|c|c|c|c|c|}
\hline & \multicolumn{5}{|c|}{ Treated series (54 patients) } & \multicolumn{2}{|c|}{ Control series (386 patients) } \\
\hline & $\begin{array}{c}\text { Group } 1 \\
20 \text { patients } \\
\text { recovered }\end{array}$ & $\begin{array}{c}\text { Group } 2 \\
12 \text { patients } \\
\text { improved }\end{array}$ & $\begin{array}{l}\text { Group } 3 \\
22 \text { patients } \\
\text { failed }\end{array}$ & Total number & $\begin{array}{c}\text { Total } \\
\text { per cent }\end{array}$ & Number & Per cent \\
\hline $\begin{array}{l}\text { Average age, years. } \ldots \ldots \ldots \ldots \ldots \ldots \\
\quad \text { Sex, males. } \ldots \ldots \ldots \ldots \ldots \ldots \ldots \\
\text { females.... } \\
\text { Antecedent factors }\end{array}$ & $\begin{array}{l}48 \\
10 \\
10\end{array}$ & $\begin{array}{r}51 \\
9 \\
3\end{array}$ & $\begin{array}{r}52 \\
16 \\
6\end{array}$ & $\begin{array}{l}35 \\
19\end{array}$ & $\begin{array}{l}65 \\
35\end{array}$ & $\begin{array}{r}50 \\
267 \\
119\end{array}$ & $\begin{array}{l}69 \\
31\end{array}$ \\
\hline 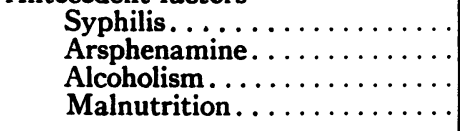 & $\begin{array}{r}4 \\
3 \\
18 \\
17\end{array}$ & $\begin{array}{r}5 \\
3 \\
11 \\
9\end{array}$ & $\begin{array}{r}5 \\
5 \\
18 \\
18\end{array}$ & $\begin{array}{l}14 \\
11 \\
47 \\
44\end{array}$ & $\begin{array}{l}26 \\
20 \\
87 \\
81\end{array}$ & $\begin{array}{r}62 \\
34 \\
207 \\
67\end{array}$ & $\begin{array}{r}16 \\
9 \\
54 \\
17\end{array}$ \\
\hline 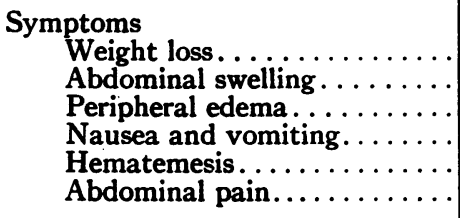 & $\begin{array}{r}16 \\
15 \\
16 \\
16 \\
7 \\
8\end{array}$ & $\begin{array}{r}9 \\
12 \\
9 \\
6 \\
2 \\
4\end{array}$ & $\begin{array}{r}17 \\
21 \\
21 \\
7 \\
4 \\
10\end{array}$ & $\begin{array}{l}42 \\
48 \\
46 \\
29 \\
13 \\
22\end{array}$ & $\begin{array}{l}78 \\
89 \\
85 \\
54 \\
24 \\
40\end{array}$ & $\begin{array}{l}206 \\
301 \\
236 \\
129 \\
106 \\
121\end{array}$ & $\begin{array}{l}53 \\
80 \\
61 \\
33 \\
27 \\
31\end{array}$ \\
\hline 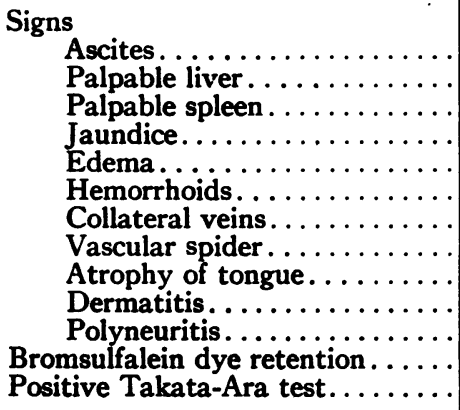 & $\begin{array}{r}15 \\
20 \\
15 \\
14 \\
15 \\
9 \\
11 \\
14 \\
15 \\
12 \\
12 \\
18 \\
16\end{array}$ & $\begin{array}{r}12 \\
11 \\
10 \\
8 \\
9 \\
6 \\
11 \\
10 \\
7 \\
5 \\
2 \\
12 \\
12\end{array}$ & $\begin{array}{l}21 \\
13 \\
13 \\
12 \\
22 \\
15 \\
19 \\
13 \\
10 \\
17 \\
7 \\
22 \\
21\end{array}$ & $\begin{array}{l}48 \\
44 \\
38 \\
34 \\
46 \\
30 \\
41 \\
37 \\
32 \\
34 \\
21 \\
52 \\
49\end{array}$ & $\begin{array}{l}89 \\
81 \\
70 \\
63 \\
85 \\
56 \\
76 \\
68 \\
60 \\
63 \\
40 \\
96 \\
91\end{array}$ & $\begin{array}{r}301 \\
291 \\
170 \\
252 \\
236 \\
105 \\
91 \\
58\end{array}$ & $\begin{array}{l}80 \\
75 \\
44 \\
65 \\
61 \\
27 \\
23 \\
15 \\
\\
13\end{array}$ \\
\hline $\begin{array}{l}\text { Average serum albumin } \ldots \ldots \ldots \ldots \\
\text { Average serum globulin } \ldots \ldots \ldots \ldots\end{array}$ & $\begin{array}{l}3.1 \\
3.7\end{array}$ & $\begin{array}{l}2.8 \\
4.1\end{array}$ & $\begin{array}{l}2.4 \\
3.9\end{array}$ & $\begin{array}{l}\text { average } 2.7 \\
\text { average } 3.9\end{array}$ & & & \\
\hline
\end{tabular}

The bromsulfalein dye test was done by the method of Rosenthal and White (a), using 5 mgm. of dye per kilo body weight. The tabulated figures refer to the per cent of dye retained by the blood serum after 30 minutes. The TakataAra test was done by the method of Heath and King (b). The serum proteins were determined by the Howe method (c).

(a) Rosenthal, S. M., and White, E. D., J. A. M. A., 1925, 54, 112.

(b) Heath, C. W., and King, E. F., New England J. Med., 1934, 211, 1077.

(c) Howe, P. E., J. Biol. Chem., 1921, 49, 109.

\section{Clinical data-comparison with a control series}

A tabulation of certain antecedent factors, symptoms, and signs is made in Table I for the $54 \mathrm{pa}-$ tients in this study. The patients are divided into three groups in order to show (1) those patients who made clinical recovery, (2) those patients whose disease was arrested or who showed partial improvement, (3) those patients who died of progressive liver failure. In the right half of the table are listed similar data obtained from a control group of hospitalized patients ill of cirrhosis of the liver. The control data are part of a statistical study of 386 cases obtained from the rec- ords of five New York hospitals during the past 20 years (22).

Several differences are apparent between the two series. The incidence of syphilis was higher in the treated series (26 per cent) than in the control series (16 per cent). Accordingly, a larger number of patients in the treated series was exposed to arsenicals. In both groups the diagnosis of syphilis was considered positive if there was a history of the treated disease, if there were clinical signs of syphilis or if repeated serological tests were positive. The possible etiologic significance of syphilis and of arsphenamine therapy in portal 
cirrhosis has been discussed by others $(23,24,25)$. Although 14 patients in the treated series had syphilis, none showed histological evidence of syphilitic involvement of the liver.

In the treated series of patients the higher incidences of alcoholism, malnutrition, and weight loss in the pre-hospital period probably are due to more complete histories. Evidence of malnutrition was striking. It may be seen in the table that 81 per cent had eaten poor diets, and that 78 per cent had lost weight (allowing for ascites). Although careful dietary histories were taken, the data were not reliable enough to measure quantitatively. The most constant defects in the diets lay in the sparing use of meat and dairy products. Many patients gave histories of having subsisted entirely on alcoholic liquor for intervals of several days and of having refused all food during these sprees.

The specific deficiency of the vitamin B complex is shown in the treated series by the high incidence of polyneuritis ( 40 per cent), of " pellagrous" dermatitis ( 63 per cent) and of atrophy of the tongue papillae (60 per cent).

The diagnosis of polyneuritis was based on signs of bilateral sensory changes (hypo- or hyperesthesia), loss of vibratory sensation, and loss of tendon reflexes in the lower extremities. Twenty-one patients showed these signs. In addition, 3 had the above changes without loss of tendon reflexes; 6 others showed the loss of vibratory sensation alone. The inclusion of these probable cases would increase the incidence of polyneuritis in the series from 40 to 57 per cent.

The relative incidence and severity of polyneuritis were greater in the females than in the males. The association of polyneuritis with cirrhosis of the liver and this peculiar sex difference have been noted by Wayburn and Guerard (26) and others. The "pellagrous" dermatitis refers to the presence of dry, scaly skin which at times was generalized and at times was limited to the extremities. Although these changes were definite, they were not associated with the inflammatory edema, severe erythema, and diarrhea that characterize frank pellagra. Except for 4 or 5 instances with marked glossitis, the atrophy of the tongue papillae was painless and of moderate degree.

In the control series of patients there are few recorded instances of vitamin deficiency, although 13 per cent showed signs of polyneuritis. It is probable that these deficiencies were overlooked, since they were not popularly known until recent years, and since the control data cover a span of 20 years.

Data showing the symptoms and signs of liver failure reveal a close agreement between the treated series and the control series of patients. It is assumed, therefore, that the severity of the underlying disease process is comparable in the two series of patients.

In the treated series certain other signs have been observed that have not been emphasized generally in the literature. Low-grade fever unrelated to infection and lasting for weeks or months has been noted in one-half the patients. Mental changes unrelated to recent alcohol intake were seen in one-third of the patients. In most instances, these were characterized by confusion and euphoria. In others a torpor was seen that simulated late cholemia. Lateral nystagmus was seen in 10 patients of whom 9 were women. These nervous changes, like polyneuritis, may be the result of coexisting nutritional deficiency $(27,28)$.

Recurrent nosebleeds were noted in 25 (46 per cent) of the cases. Vascular "spiders" of the skin (30) were observed in 68 per cent of the cases. Macrocytic anemia, usually moderate in degree, was present in 40 per cent of the patients. Except in 2 patients with hypertensive heart disease and 2 others who may have had beriberi heart, there was no evidence of heart failure in these patients. In 20 patients with ascites the venous pressure in the antecubital vein and the circulation time were within normal limits.

Certain laboratory data from the treated series are likewise included in the table. In 96 per cent the blood serum showed abnormal retention of bromsulfalein dye; in 91 per cent, a positive Takata-Ara test. The initial serum albumin value was low (below 4.0 grams per cent) in 96 per cent of the patients. The initial serum globulin value was high (above 3.0 grams per cent) in 83 per cent of the patients. It is noteworthy that the average initial value for serum albumin is higher in those patients who made clinical improvement than in those who failed to improve.

\section{Program of therapy}

In Table II is outlined the dietary regimen employed. The diet differs radically from that commonly advocated in this country for the treatment of cirrhosis of the liver, which is high in carbohydrate but low in protein and fat. The present diet contains a moderate amount of protein and fat. In addition to the protein of the diet (114 grams) the patients receive $\mathbf{5 0}$ grams of powdered 
TABLE II

Standard diets for cirrhosis patients

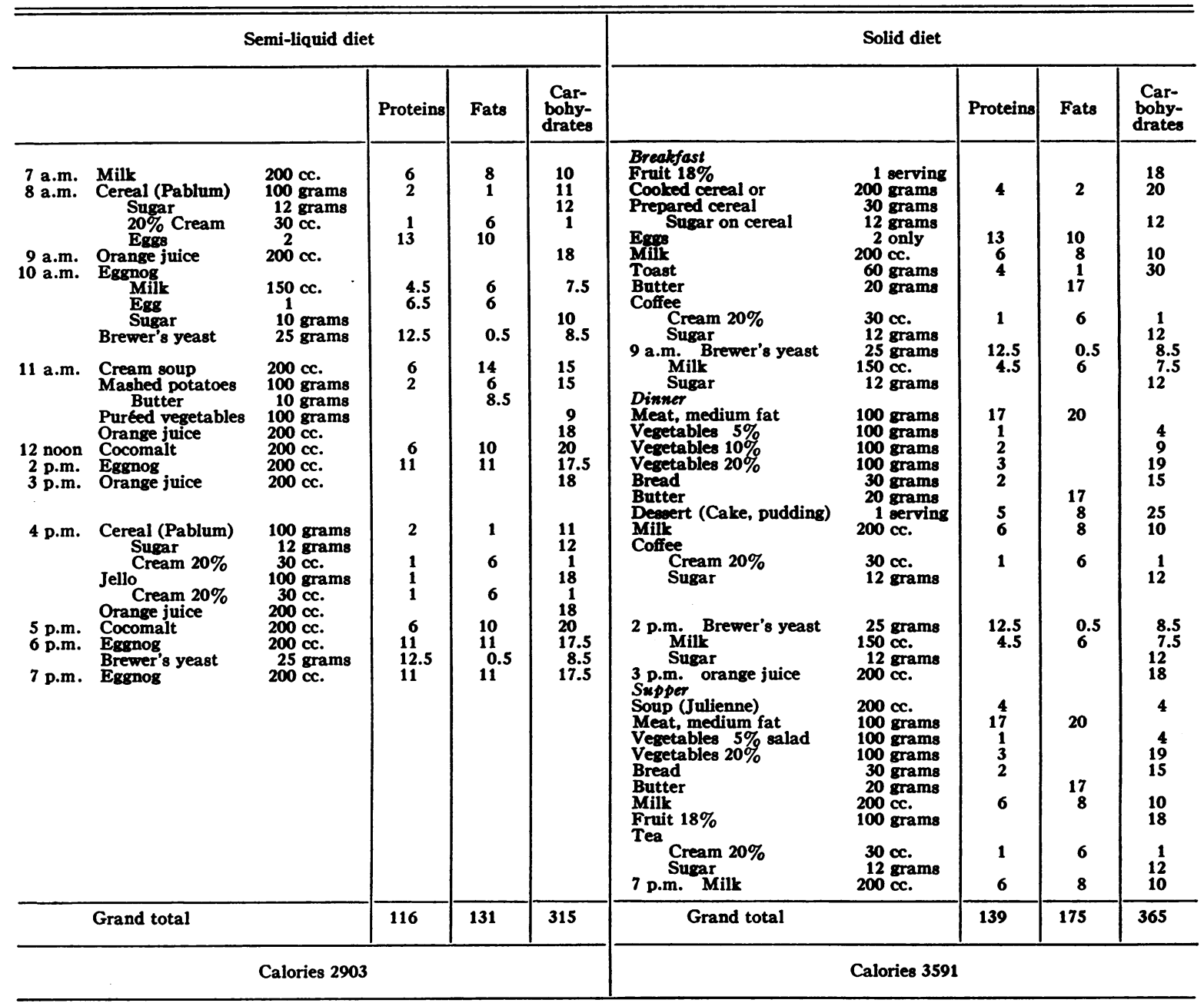

The semi-liquid diet was used only in the exceptional cases when patients either refused or were unable to take the solid diet. Brewer's yeast was fed in a milknog, according to the method described by Spies, Chinn, and McLester (a). The yeast was stirred thoroughly in cold milk, and flavored with sugar, vanilla, and nutmeg.

The writers are indebted to Miss Josephine Henneberger for the preparation of the diets.

(a) Spies, T. D., Chinn, A. B., and McLester, J. B., J. A. M. A., 1937, 108, 853.

Brewer's yeast ${ }^{2}$ daily, of which the protein content is about 50 per cent. There has been no evidence of intolerance to fat in the amounts given. The stools do not contain excessive fat. Salt intake is restricted in patients with ascites and edema to the extent of omitting a salt shaker from the tray, and fluids are allowed up to 2,000 cc. daily. In the first group of 13 patients reported (21), vitamin B “ complex" was provided daily in the form of autolyzed yeast (Vegex) or

2 Harris Laboratories, Tuckahoe, N. Y.; Mead Johnson \& Co., Evansville, Indiana. of aqueous liver extract (Valentine). Brewer's yeast was then substituted for these concentrates because it was found to be more palatable in large amounts. In addition to the yeast, the patients generally received intramuscular injections of concentrated liver extract, 5 cc. twice weekly (Lilly or Lederle), and of thiamin chloride, ${ }^{8} 5 \mathrm{mgm}$. daily. In patients with severe neuritis, thiamin chloride was administered in doses of 10 to 20

3 Thiamin chloride was generously supplied by Merck \& Co., Rahway, N. J., and by the Winthrop Chemical Co., New York City. 
mgm. daily. Concentrates of vitamins $A$ and $D$ were fed only to the first series of 13 patients (21).

\section{Grouping of patients according to clinical course}

For the sake of convenience, the patients were placed in three groups, as described previously (Table I). The case histories of the patients are listed according to these three groups. Group 1 includes those whose course was characterized by steady improvement with clinical recovery; Group 2 includes those who made partial clinical improvement and also those cases who improved but who were followed too short a time to permit inclusion in Group 1; Group 3 includes those who died after progressive liver failure.

The typical patient with cirrhosis of the liver might be described as follows: Characteristically, he has been bedridden for weeks or months. He has lost much weight. At entry he is weak and tired, mentally dull and at times confused. Food is loathsome. He complains of thirst, of abdominal fullness and pain. There is often lowgrade fever. The pulse rate is rapid. Breathing is shallow because of an elevated diaphragm. The urine output varies from 300 to $1,000 \mathrm{cc}$. daily. Abdominal hernia, hemorrhoids, nosebleeds, and polyneuritis may contribute to his disability. In those patients who fail to respond to treatment, the above symptoms and signs persist and become more severe: Ascites accumulates rapidly. Jaundice may become intense, and generally, after 1 to 3 months in the hospital, the patient dies in cholemia from intercurrent infection or from hemorrhage.

The changes that indicate improvement are gradual and slow in appearing. The nursing care at this critical stage must be as meticulous and vigilant as that given the patient with typhoid fever. Subsidence of fever, recovery of appetite, return of mental clarity and gain in strength gradually take place. With increase in the urinary output the ascites and edema disappear. This transition usually requires about 2 months. It has varied from 2 weeks to 10 months.

Although jaundice usually is of low grade, it takes weeks or months for this to subside completely. In most cases no appreciable change is noted in the size of liver or spleen. However, abdominal pain and tenderness always subside with the patient's clinical improvement.

Six patients who had hematemeses in the past have had no recurrence for from 2 to 4 years. The cessation of nosebleeds has been observed in many patients; the disappearance of vascular "spiders" has been observed in 10 patients; and the reappearance of menses after protracted amenorrhea has been experienced by 4 women.

Changes in the laboratory findings have accompanied the clinical improvement. In 33 cases the value for serum albumin has increased significantly. The elevated serum globulin has fallen in 23 cases. The Takata-Ara test has changed from positive to negative in 19 instances. A diminished retention of bromsulfalein dye has accompanied improvement in 18 instances. The degree of change in the dye test, however, has not been striking. Changes in the cephalin flocculation test have reflected improvement in a significant number of cases. These findings will be reported elsewhere by Hanger (32). In almost all cases the blood counts and hemoglobin approached normal values.

Recovery from polyneuritis in these patients is slow and usually incomplete. Functional improvement is striking in most instances, but the return of vibratory sensation may be partial, and the tendon reflexes may fail to return even after several years of intensive treatment with vitamin B concentrates. The pellagrous dermatitis and the atrophy of the tongue papillae generally respond to therapy within a few weeks.

Group 1. Patients whose course showed clinical recovery from symptoms and signs of cirrhosis. It may be seen in Table I that this group of $20 \mathrm{pa}-$ tients with few exceptions showed plain evidence of liver decompensation before treatment was begun. Improvement was gauged by the following criteria : (1) gain in weight and strength, permitting the patient to resume fully his previous activities; (2) loss of ascites, edema, and jaundice without recurrence; (3) changes of serum proteins, Takata-Ara and bromsulfalein dye tests towards normal values.

Included in this group are 5 patients (Cases 22, $23,24,25,30$ ) who lost ascites and who were maintained in good health, but who died from complications that were not ascribable to liver failure. 
Group 2. Patients who made partial improvement. There are 12 patients whose course showed signs of partial improvement. Five of these correspond in the degree of improvement to that noted in Group 1. Because the follow-up after discharge from the hospital has been limited to 4 , $5,6,6$, and 8 months, respectively, they are classed tentatively in Group 2. Three other patients have remained ascites-free for many months after having required abdominal taps in the past, but they are not in robust health. Although the serum albumin increased, it did not reach normal values in this group. Finally, there are 4 patients whose ascites disappeared and who were ambulatory but not vigorous. They subsequently died after being ascites-free for more than 2 years in each instance (cf Cases 26, 27, 28, 29).

Group 3. Patients who died after progressive liver failure. The survival period of this group of 22 patients varied from 2 days to 14 months after entry to the hospital. Only 4 of this group survived more than 5 months after entry. It is noteworthy that 11 of the 22 deaths occurred within 1 month of admission to the hospital. In many instances they were able to eat but a small portion of the prescribed diet. Histories of Cases 11, 19 and 21 are included since they are unusual. Histories of Cases 8 and 13 are included as typical of the remaining case histories in this group.

Effect of administration of alcohol. Since the routine treatment of these patients involves not only dietetic care but also the denial of alcoholic liquors, it seemed pertinent to test the effect of the administration of alcohol on a selected group. These 4 patients (Cases 41, 51, 46, 44) previously had strong alcoholic backgrounds. On admission to the hospital they presented varied degrees of liver failure. After they had shown signs of clinical improvement they were fed alcohol in addition to the nutritious diet and vitamin $\mathrm{B}$ concentrates described. Nine ounces of 40 per cent alcohol were fed daily as a fruit juice tonic for 6, 6, 14 and 18 months, respectively. There was no recrudescence of their former symptoms or signs, such as jaundice or ascites. The bromsulfalein dye test, Takata-Ara test, and the serum proteins showed no adverse changes. A fifth patient (Case 42), a barkeeper who has resumed his former trade, admits drinking six to eight glasses of beer daily in the past $1 \frac{1}{2}$ years since discharge from the hospital. There has been no relapse in the clinical status of this patient who was severely decompensated at entry.

Causes of death. The causes of death in the fatal cases are listed in Table III. There are 14

TABLE III

Causes of death in 31 patients with cirrhosis of the liver

\begin{tabular}{|c|c|}
\hline Number & Autopsies \\
\hline 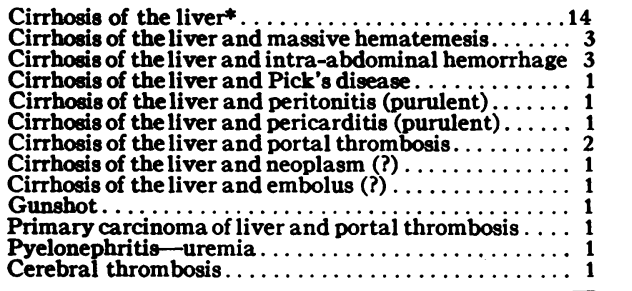 & $\begin{array}{l}\mathbf{8} \\
\mathbf{3} \\
\mathbf{2} \\
\mathbf{1} \\
\mathbf{1} \\
\mathbf{1} \\
\mathbf{1} \\
\mathbf{0} \\
\mathbf{0} \\
\mathbf{1} \\
\mathbf{1} \\
\mathbf{1}\end{array}$ \\
\hline Total..............31 & 21 \\
\hline
\end{tabular}

* Terminal lobular pneumonia in 7 cases.

cases in which cirrhosis of the liver was the apparent primary cause of death. In addition to these are listed 13 instances in which certain complications of cirrhosis precipitated death. Finally, there are listed 4 cases in which the cause of death was unrelated to cirrhosis of the liver, although histological evidence of cirrhosis was present as well.

\section{Statistical comparison of the present (treated) series and a control series with respect to the duration of life}

In order to estimate the effectiveness of the dietary regimen employed here, a comparison was made with the control series of 386 patients previously mentioned. Ideally, in a study of prognosis, the length of life should be determined from the date of onset of the disease. In the case of cirrhosis of the liver this is impossible because the early symptoms may be vague or entirely masked. Moreover, the patient, disabled by his disease, is unable to recall details of the beginning of his illness, which may have preceded the mature process by years. For these reasons it is more appropriate to select an objective sign, like ascites, which permits fairly easy and accurate recognition by the patient.

Since the patients at the Research Service were transferred from other hospitals, it is possible that the treated series fails to include certain patients 
who would have died shortly after the onset of liver failure. In this way a bias would be introduced into the results. For example, in the control series 50 patients died and 16 patients were dropped from observation within 1 month of the onset of ascites. No such loss occurred in the treated series. In comparing the survival of the two series of patients, allowance was made for this degree of selectivity by excluding those patients who died or were "lost" within the first month.

$\mathrm{We}$ are indebted to Mr. Herbert $\mathrm{H}$. Marks of the Metropolitan Life Insurance Company for the following analysis of the data:

A survivorship table was prepared, both for the treated cases and the controls, classified by individual months from the second through the eighth month, and by broader time groups beyond, namely for the ninth to twelfth months combined and for the second year. The experience past the second year is too small to be reliable. The experience for the first month was excluded from both series because the treated series consists very largely of cases referred from other hospitals and only a much smaller percentage were actually observed within a month of onset of ascites than in the control series. Elimina- tion of this first month after onset of ascites largely reduces a bias in favor of the treated group.

The survivorship data are shown in detail in Table IV and the table has been so annotated that the method of computation can be followed. The last column of the table is presented graphically in Figure 1. Attention should be called to the fact that the method is approximate only, but the nature of the material and the small size of the samples do not warrant more refined analysis.

The greater longevity of the treated series is clear from the chart. Thus, the proportion surviving at the end of 6 months was 72 per cent of the treated series, compared with 57 per cent in the controls. At the end of the first year, 57 per cent of the treated group survived, but only 39 per cent of the controls. At the end of the second year, these ratios were 45 per cent and 21 per cent, respectively.

Mortality rates likewise were computed from Table IV. These are shown graphically in Figure 2. It is evident that during the first and second years after the onset of ascites the mortality rates were definitely lower in the treated series than in the controls.

TABLE IV

Survival of patients with cirrhosis of the liver from onset of ascites

(Comparison of cases treated at Research Service from August 1936 to November 1940, with a control group from several hospitals, from 1920 to 1940.)

TREATED SERIES

\begin{tabular}{|c|c|c|c|c|c|c|}
\hline Period* & $\begin{array}{c}\text { Number observed } \\
\text { at beginning } \\
\text { of period }\end{array}$ & $\begin{array}{c}\begin{array}{c}\text { Died } \\
\text { during the } \\
\text { period }\end{array} \\
\text { B }\end{array}$ & $\begin{array}{c}\begin{array}{c}\text { Dropped from } \\
\text { observation } \\
\text { during the period }\end{array} \\
\text { C }\end{array}$ & $\begin{array}{l}\text { Proportion dying } \\
\text { during the period } \\
\text { of those observed } \\
\text { at beginning of } \\
\text { period (q) } \\
D=B / A\end{array}$ & $\begin{array}{l}\text { Proportion living } \\
\text { at end of period } \\
\text { of those observed } \\
\text { at beginning of } \\
\text { period }(p=1-q) \\
\qquad E=1-D\end{array}$ & $\begin{array}{c}\text { Proportion } \\
\text { surviving at end } \\
\text { of period of } \\
\text { original } \\
\text { cohort (1) } \\
F\end{array}$ \\
\hline 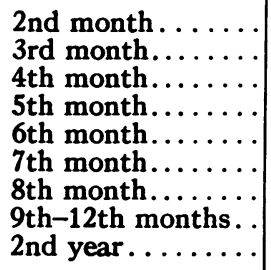 & $\begin{array}{l}47 \\
46 \\
44 \\
41 \\
38 \\
33 \\
31 \\
29 \\
24\end{array}$ & $\begin{array}{l}1 \\
2 \\
3 \\
3 \\
4 \\
2 \\
1 \\
4 \\
5\end{array}$ & $\begin{array}{l}1 \\
1 \\
1 \\
6\end{array}$ & $\begin{array}{l}0.021 \\
0.043 \\
0.068 \\
0.073 \\
0.105 \\
0.061 \\
0.032 \\
0.138 \\
0.208\end{array}$ & $\begin{array}{l}0.979 \\
0.957 \\
0.932 \\
0.927 \\
0.895 \\
0.939 \\
0.968 \\
0.862 \\
0.792\end{array}$ & $\begin{array}{l}0.979 \\
0.937 \\
0.873 \\
0.809 \\
0.724 \\
0.680 \\
0.658 \\
0.567 \\
0.449\end{array}$ \\
\hline \multicolumn{7}{|c|}{ CONTROL SERIES } \\
\hline 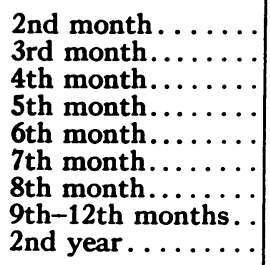 & $\begin{array}{r}230 \\
174 \\
141 \\
125 \\
111 \\
94 \\
83 \\
75 \\
46\end{array}$ & $\begin{array}{r}41 \\
21 \\
8 \\
10 \\
10 \\
9 \\
6 \\
14 \\
21\end{array}$ & $\begin{array}{r}15 \\
12 \\
8 \\
4 \\
7 \\
2 \\
2 \\
15 \\
4\end{array}$ & $\begin{array}{l}0.178 \\
0.121 \\
0.057 \\
0.080 \\
0.090 \\
0.096 \\
0.072 \\
0.187 \\
0.457\end{array}$ & $\begin{array}{l}0.822 \\
0.879 \\
0.943 \\
0.920 \\
0.910 \\
0.904 \\
0.928 \\
0.813 \\
0.543\end{array}$ & $\begin{array}{l}0.822 \\
0.723 \\
0.682 \\
0.627 \\
0.571 \\
0.516 \\
0.479 \\
0.389 \\
0.211\end{array}$ \\
\hline
\end{tabular}

* First month after onset of ascites excluded. 
It may be repeated that both the control and treated series are derived from the same socialeconomic levels; that the average ages of the two groups are the same; that the same criteria for diagnosis were applied to both series of patients; that the degree of liver failure as judged by symptoms and signs in Table I corresponds closely in the two series. However, in statistical comparisons of this kind there are uncontrolled factors which tend to favor one or the other group. For example, the control series of cases was taken from records over a 20 -year period. It is possible that the character of the disease has changed in recent years. The period of hospitalization is longer in the treated than in the control series. Despite these sources for error, the differences between the control and treated series appear to be significant.

Prognosis after entry to the hospital. There is one further serious source of error inherent in the statistical methods employed above. The accuracy of the data depends on the accuracy of the patient's definition as to when ascites formation began. Therefore, it seemed advisable to compare the two

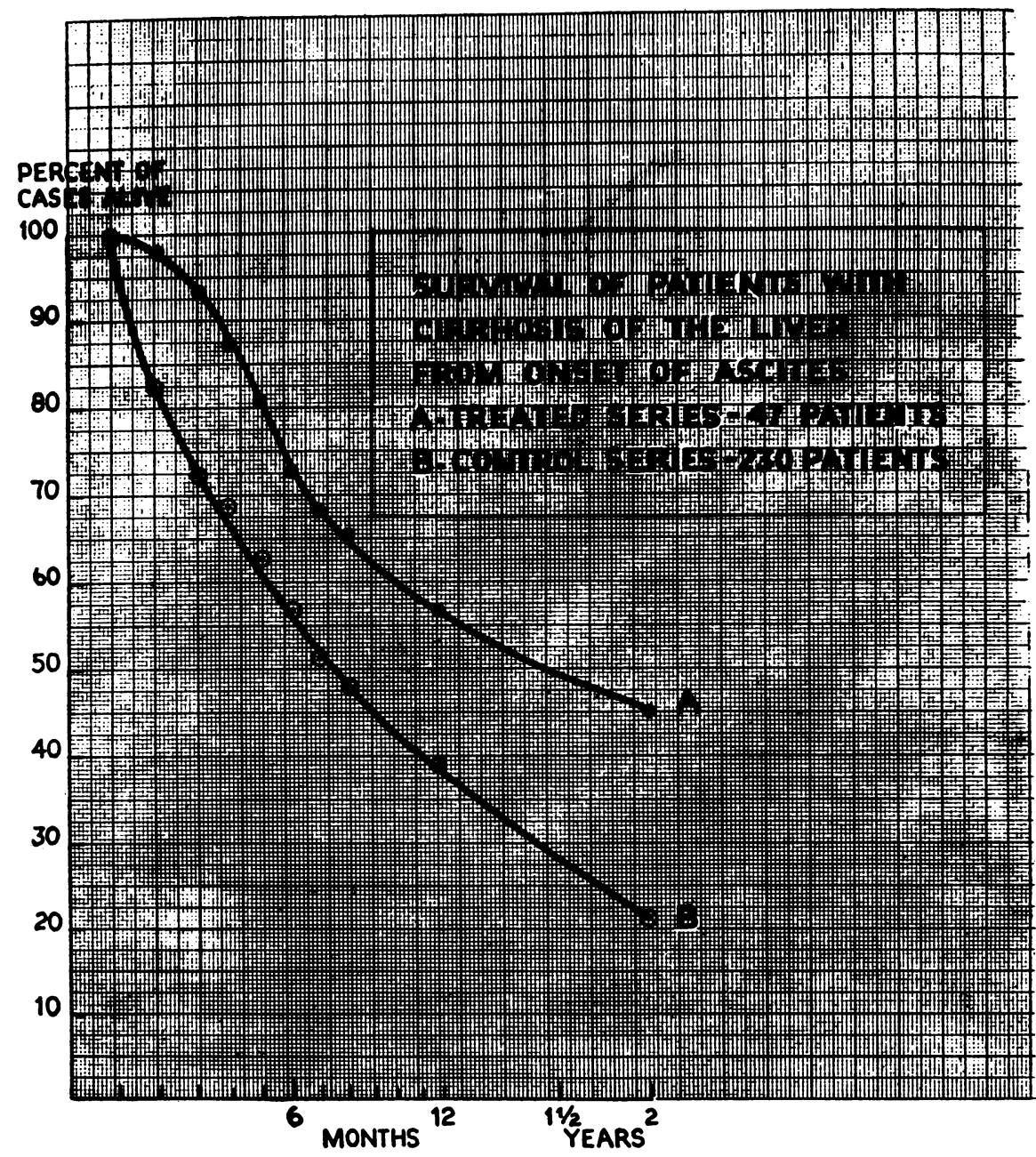

Fig. 1. Survival of Life After the Onset of Ascites in Patients with Cirrhosis OF THE LIVER

The proportion surviving at the end of each period (Table IV, column $F$ ) is multiplied by 100 to convert to the per cent of cases surviving. Computations beyond the second year are not used because the number of cases beyond that point in the treated series is too small. 


\section{MORTALITY RATES IN CIRRHOSIS OF LIVER}

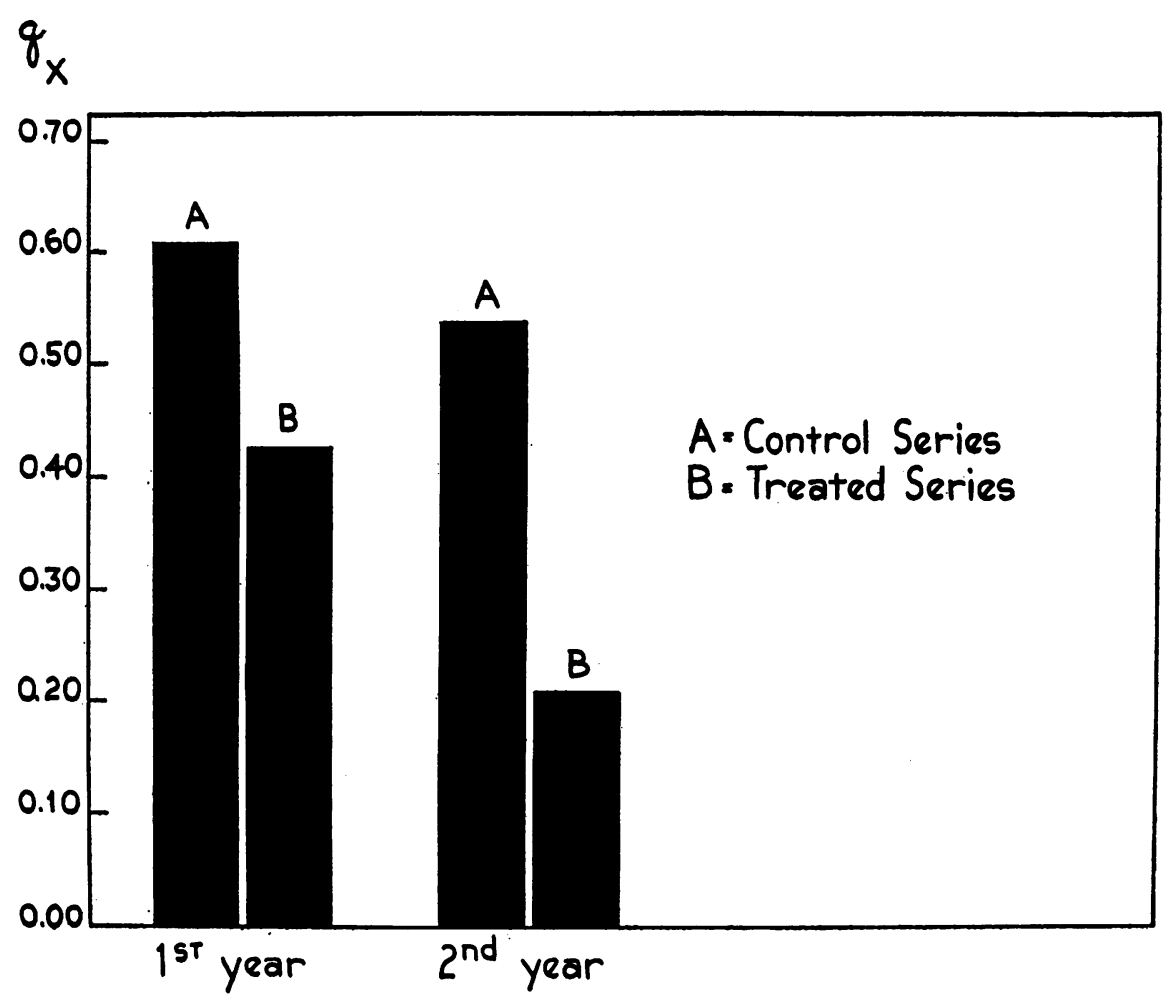

Fig. 2. Death Rates $(q x)$ Per Annum in Cirrhosis of the Liver During the First and Second Years After the Onset of Ascites

Comparison of control series and treated series.

series of patients from dates of first actual observation, when they were under medical supervision. Figure 3 illustrates the duration of ascites before and after entry to the hospital in the series of 47 treated patients. It is evident that about one-half of these patients lost ascites after treatment in the hospital. Several patients, whose ascites had disappeared for considerable periods of time and who had made clinical recovery from cirrhosis, died from intercurrent illness or accident.

Figure 4 illustrates the duration of ascites before and after entry to the New York Hospital ${ }^{4}$ of 102 unselected patients with cirrhosis of the liver and ascites. (These form part of the control series of 386 cases.) In contrast to the treated series, there are less instances of remission from ascites in the control group. In 3 of the 7

${ }^{4}$ We are indebted to Dr. Eugene Dubois for permission to study these case records. instances * in which ascites disappeared, the patients had received vitamin $\mathrm{B}$ concentrates. Likewise, the period of survival after entry to the hospital appears to be significantly less in the control group than in the treated series of 47 patients.

\section{DISCUSSION}

\section{Comparison of mortality data in medical literature}

There are few data available in the medical literature which provide a norm for comparison with the present series of cases. In earlier reports cited by Patterson (33) and by Chapman, Snell, and Rowntree (34), the average life expectancy after the onset of ascites varied from 1 to 6 months. In a series of 38 cases Rolleston and $\mathrm{McNee}$ (35) reported an average life expectancy of 3 to 4 months after the onset of ascites; whereas Henrikson (36) reported an average duration of 12.8 months in a series of 42 patients

* Spontaneous loss of ascites occurred in 7 per cent of 386 cases. 


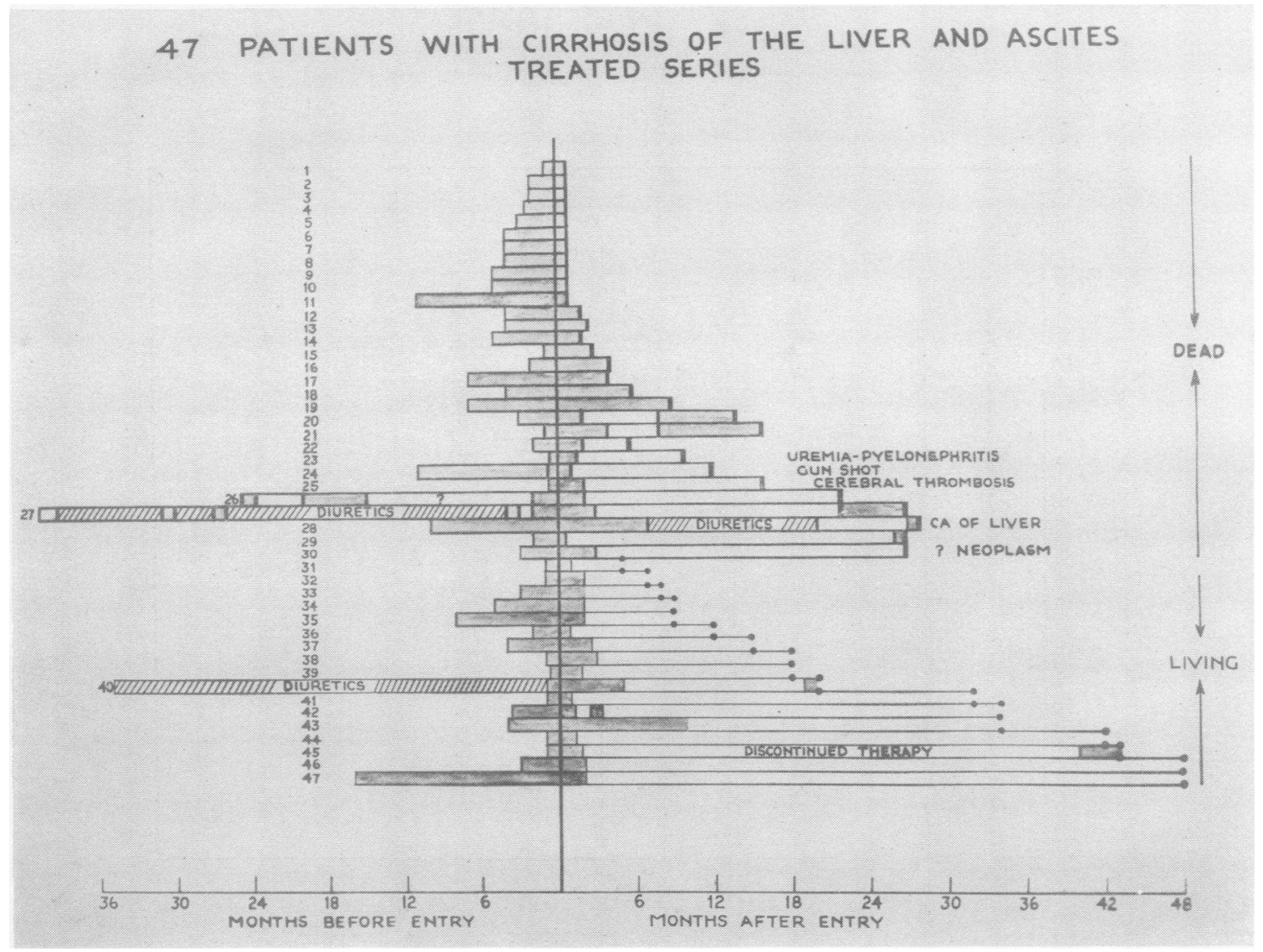

Fig. 3. Clinical Colrse of 47 Patients With Cirrhosis of the Lifer axd Ascites (Treated Series)

The central black line denotes the date of entry to the hospital. Time preceding entry is represented by columns to the left of this line. whereas time after entry is represented by columns to the right of the line. Shaded areas indicate the presence of ascites. The closed columns indicate a fatal issue. The open columns indicate that the patient was alive at the time of this analysis.

receiving no specific therapy. In his analysis of 372 cases Eppinger (37) gave no data on prognosis, but he stated that once abdominal paracentesis was performed, a fatal outcome was imminent. In contrast to this rather gloomy picture are numerous case reports $(33,34,38,39)$ of spontaneous recoveries, in which patients lived years after the disappearance of ascites. A1though these are of interest, they are of limited value from a statistical point of view. Moreover, it is doubtful that recovery from a disease process occurs " spontaneously." Doubtless a cause exists for this change.

Because of the wide differences in the medical literature concerning the natural history of the disease, our treated series was compared only with our own control series.

\section{Other forms of treatment}

The treatment of cirrhosis of the liver by other medical measures and by certain surgical procedures has been adrocated. Chapman. Snell, and Rowntree (34) reported on the use of saline and mercurial diuretics in 84 of 112 carefully selected patients with decompensated portal cirrhosis, all of whom had ascites. The average duration of life after ascites appeared was 16 months. Twentyfive of these patients survived an average of 32 months after the onset of ascites. Jones and Eaton (40) have reported on the favorable effect of glucose infusions and a high carbohydrate diet in 50 patients with disease of the liver. The majority of their patients represented acute or subacute hepatitis, in which jaundice was the prominent feature. In 10 instances ascites was present. 


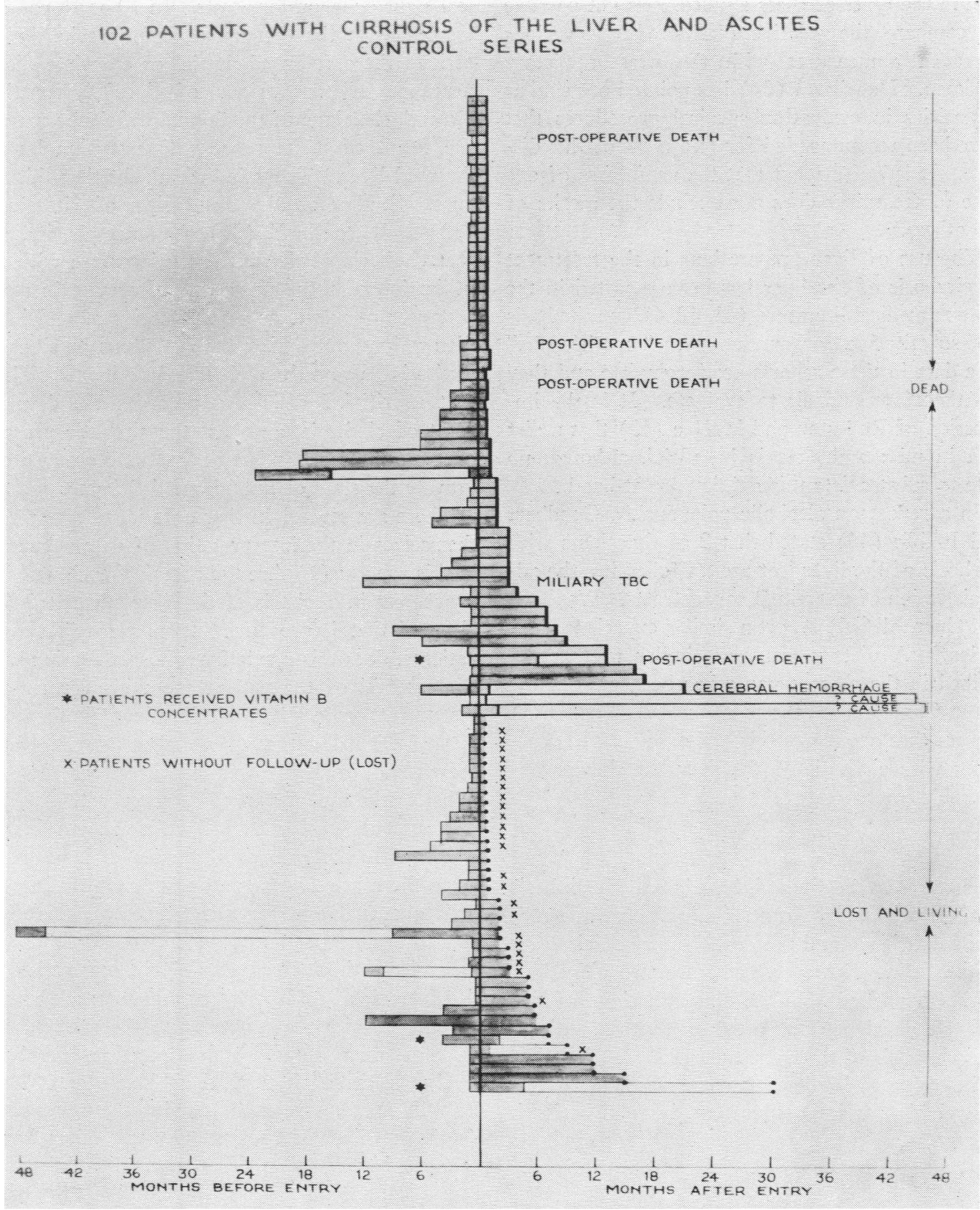

Fig. 4. Clinical Course of 102 Patients With Cirrhosis of the Liver and Ascites (New York HosPITAL--CONTROLS)

The symbols correspond to those of Figure 3 . 
Because of differences in the selection of cases and in the types of cases studied, it is not possible to compare the relative merits of the various therapeutic measures with the present dietary regimen. Henrikson (36) has pointed out similar difficulties in evaluating surgical procedures that have been recommended for treatment of this disease. It is self-evident that the usefulness of one type of treatment does not exclucle the merits of the others.

The use of liver preparations in the treatment of cirrhosis of the liver has been reported in the French medical literature $(41,42,43)$ on the basis of substitutive organotherapy, "opothérapie." The data in these reports are incomplete and they are therefore difficult to evaluate. It is the impression of Rolleston and McNee (35) that a diet rich in milk and eggs is beneficial, although no data to substantiate this opinion are at hand.

In a report on alcoholic polyneuritis. Goodhart and Jolliffe (44) stated that 2 of 6 patients with cirrhosis of the liver lost ascites following the administration of vitamin B concentrates. Wayburn and Guerard (26) report a similar experience in 1 patient. A dietary program similar to that described in the present paper has been used at the Mayo Clinic during the past 2 years. Snell (45) reports that about one-third of a series of 50 patients with cirrhosis of the liver has shown considerable improvement.

\section{Interpretation of data}

The present treatment is based on the hypothesis that there is a significant relation between nutritional deficiency and the development of cirrhosis of the liver. However, there are two objections to this hypothesis. First, although signs of nutritional deficiency are often present in patients with cirrhosis of the liver, the incidence of cirrhosis in patients with deficiency diseases is not necessarily high. It is possible that, in fatal beriberi, pellagra, and sprue, patients die before cirrhosis of the liver can develop. Not infrequently the livers of such patients at autopsy show degenerative changes $(48,49)$. The observation that liver damage may occur in these diseases is supported by our experience with 24 patients admitted to the hospital primarily for nutritional deficiency. Of these, 22 were alcoholics with polyneuritis; 3 also had pellagra and 2 had sprue. Twenty of the 24 patients showed evidence of liver injury by physical signs or laboratory tests. In 10 of 15 patients treated with the dietary regimen previously described there followed partial or complete disappearance of these signs of liver dysfunction. Second, the signs of nutritional deficiency may be the result of interference with nutrition by the diseased liver. There is little doubt that this occurs. Studies on the metabolism of vitamin A (50) and vitamin $K$ (51), for example, indicate that cirrhosis of the liver may interfere with the utilization of these vitamins. However, in many instances our patients gave histories of deficiency disease long antedating the symptoms or signs of cirrhosis. From these observations it seems likely that nutritional deficiency precedes the development of cirrhosis. and that the cirrhotic process, once established, tends to perpetuate or even aggravate the state of nutritional deficiency.

There are several further questions that present themselves in the interpretation of data submitted in this report: (1) Are the criteria for clinical improvement in cirrhosis of the liver adequate? (2) Granted that improvement takes place in certain patients, does this result from hospitalization with the removal of the patient from his former environment, or does it result from specific therapy? (3) If clinical improvement takes place, is there corresponding change in the liver structure? ( $t)$ What is the mechanism of "recovery"?

The evidence for clinical improvement in patients with cirrhosis of the liver is inadequate, since there are few signs or tests which may be used quantitatively for this purpose. It is difficult to separate signs of general bodily improvement from those that pertain to the function of the liver alone. Although certain tests are useful for the diagnosis of acute hepatitis, such as the galactose-tolerance and hippuric acid tests and the level of serum cholesterol, these have been of little help, in our experience, in gauging the presence or degree of liver cirrhosis. On the other hand, changes in the value for serum albumin correspond in most instances with changes in the clinical condition of the patient (31). The cephalin flocculation reaction likewise has reflected corresponding clinical changes. The bromsulfalein and Takata-Ara tests are useful as qualitative rather than quantitative measures.

In this report stress is laid on the disappearance 
of ascites as a sign of improvement. It is realized that the disappearance of a sign of liver failure does not necessarily indicate a remission in the underlying disease process. However, the statistical evidence for decreased mortality rate, and the clinical evidence for bodily improvement in these patients, support the impression that the disease process has been modified. Admittedly, the criteria for improvement are inadequate, but to the clinician and to the patient the improvement is no less real.

There is little doubt that hospitalization and the removal of the patient from his former environment are beneficial. However, a control group of 386 patients who received hospital care does not show a comparable trend toward improvement. The two groups are not strictly comparable since the larger series had less prolonged hospital care. It is perhaps more significant that 4 patients with cirrhosis of the liver, who previously had an alcoholic background and who had shown signs of liver failure, were given 9 ounces of 40 per cent alcohol daily for from 6 to 18 months with no untoward effects. It may be argued justly that the amounts of alcohol administered were relatively small, according to the patients' habitual intake. Of necessity, this point could not be tested fully.

There is little, if any, evidence from the present data of correlation between clinical and histological changes in the liver. In the patients who died, presumably of liver failure, the histological picture of the liver showed wide differences. Within broad limits, it was impossible to tell the degree of liver competence by the histological picture. Similar difficulties with biopsy material are reported by Cates (46). In 2 patients who showed partial improvement for over 2 years, and who then died (Cases 28 and 29), there was marked necrosis of liver cells and periportal fibrosis similar in degree to the cirrhosis of patients who died after a rapid failure of several weeks. In 3 patients (Cases 23, 24 , and 25) who had signs of liver failure with ascites on entry, and who made more or less complete clinical recovery but later died of non-hepatic lesions, the degree of cirrhosis at autopsy appeared to be minimal. Since biopsies were not done at entry, one can only speculate on anatomical changes that may have occurred. If anatomical changes were found, the evidence would be sug- gestive. The absence of anatomical change would not imply necessarily a lack of functional change.

It is realized that cirrhosis of the liver often is discovered at autopsy in persons dying from other causes. In these cases cirrhosis may have been latent for many years. In a series of 245 autopsies that showed cirrhosis of the liver, McCartney (47) found that 35 per cent had no previous clinical manifestations of the disease. The present series obviously does not include latent cases, but treats only of those who showed evidence of failure of the liver during life.

The present data give no indication as to whether vitamin B concentrates, protein, or some unknown substances are specifically effective in the treatment of cirrhosis. It is possible that, by maintaining patients in optimal nutrition and rest, the liver recovers "spontaneously". In other words, the present regimen may allow the patient to survive long enough for natural reparative processes to take effect. It is also possible that the present regimen provides a specific agent for recovery of the diseased liver. The fact that only a limited number of patients survive despite therapy does not rule out the latter possibility. When the diagnosis of cirrhosis of the liver can be made in the incipient stages, the mortality rate should become much reduced for, unlike most other vital organs of the body, the liver has the capacity to regenerate. In this capacity lies the hope for an effective therapy.

\section{SUM MARY}

In summary, the present studies indicate that the treatment of cirrhosis of the liver by a highly nutritious diet supplemented with vitamin B concentrates is of therapeutic value. This is inferred from a comparison of 54 patients so treated with a control series of 386 patients with cirrhosis of the liver. Following the onset of ascites, 72 per cent of the treated series, as compared with 57 per cent of the controls, survived 6 months. At the end of the first year, 57 per cent of the treated series survived, but only 39 per cent of the controls. At the end of the second year, 45 per cent of the treated series, as compared to 21 per cent of the controls, were still alive.

In addition to an increased period of survival, there are signs of general bodily improvement and presumptive evidence of arrest of the disease 
process. In a significant number of patients there has been disappearance of ascites, edema, jaundice, and of vascular "spiders". Certain laboratory data, such as the level of the serum albumin and of the serum globulin, the Takata-Ara test, cephalin flocculation test, and bromsulfalein dye test, have reflected corresponding improvement.

From the above evidence it seems clear that cirrhosis of the liver is not necessarily committed to a continuous, progressive course.

Since the treatment of the 54 patients involved a number of factors, the improvement may not be attributed to a specific agent.

The coexistence in these patients of nutritional deficiency and cirrhosis of the liver is striking. However, the relation of nutritional deficiency to cirrhosis is not clear. Certain experimental studies as well as the present clinical observations suggest that nutritional deficiency predisposes to the development of cirrhosis of the liver, and that cirrhosis of the liver, once established, tends to perpetuate the state of nutritional deficiency.

The etiologic relationship, if it exists, between nutritional deficiency and cirrhosis of the liver could be either direct or indirect. It is possible that the lack of certain food factors leads directly to the development of cirrhosis. It is also possible that the malnourished liver becomes vulnerable to toxins which ordinarily would be disposed of.

\section{CONCLUSIONS}

1. Evidence is presented which suggests that there is a significant relationship between the occurrence of nutritional deficiency and cirrhosis of the liver.

2. Fifty-four patients with cirrhosis of the liver were treated with a highly nutritious diet supplemented by vitamin B concentrates. The clinical course of the patients appeared to be more favorable than that of a control series of 386 hospitalized patients with cirrhosis of the liver.

\section{CASE HISTORIES ${ }^{5}$}

\section{Group 1}

Case 31. A 29-year-old Italian machinist entered the hospital on February 14, 1939, because of abdominal

5 When it is not specifically stated, the dietary regimen was begun after entry of the patient to the Research Service. swelling. Seven years previously pallor, weakness, and tarry stools had been observed. Three years. previously jaundice had been present for several weeks. One month before admission there was sudden mid-abdominal pain, nausea, and vomiting for 1 day, followed abruptly by onset of ascites and jaundice. There was no response to diuretics. After one abdominal tap, ascites recurred. Exploratory operation was performed 2 weeks later. Liver and spleen were enlarged. Biopsy showed portal cirrhosis. One abdominal tap was performed after operation. Chief findings were: ascites, edema, palpable liver and spleen, vascular "spiders"; RBC 4.4, Hgb. $71 \%$, WBC 3,500 , serum albumin 3.3 , serum globulin 3.2, bromsulfalein 25 to $30 \%$, icteric index 6 .

Dietary therapy was begun after operation. There was steady gain in weight and strength; ascites and edema disappeared in 1 month; serum albumin rose to 4.3; bromsulfalein remained $30 \%$. The patient left against advice on June $29,1939,41 / 2$ months after entry. He moved from the city and there was no follow up.

Case 24. A 52-year-old colored waiter entered the hospital on April 28, 1937, because of abdominal swelling. He was a chronic alcoholic. A large liver had been noted $11 / 2$ years previously and 1 year before admission onset of ascites had occurred. He received eight abdominal taps at about monthly intervals preceding entry. Edema of legs was present for 2 weeks. There was no jaundice. His usual weight was 180 . Chief findings were: ascites, edema, palpable liver and spleen; RBC 4.5, Hgb. $87 \%$, WBC 9,400, serum albumin 3.2, serum globulin 3.8 , Takata + , bromsulfalein $40 \%$, icteric index 5. No neurological changes.

After entry, abdominal tap was done with removal of 11,000 cc. of fluid. Dietary therapy was then begun. Massive diuresis occurred during succeeding 2 weeks. Weight fell from 191 to 149 lbs. in 1 month and returned to $165 \mathrm{lbs}$. in the following 2 months without recurrence of ascites or edema. The patient left the hospital against advice on September 24, 1937, 5 months after entry. At this time serum albumin was 4.7 , globulin 3.7 , Takata negative, bromsulfalein $16 \%$. He was seen at home on December 10, 1937, when he felt well. Liver was palpable but spleen was not felt. There was no ascites. He admitted drinking whiskey. Serum albumin at this time was 4.9 , globulin 3.3 ; bromsulfalein $40 \%$. He died from a gun shot wound on March 2, 1938. Gross changes at medico-legal autopsy showed thickened capsule of liver and spleen. No further description was available.

Case 37. A 36-year-old American-born stenographer entered the hospital on July 3,1939, because of abdominal swelling. She had had typhoid at 10 years; was a chronic alcoholic. Her diet was poor in meat and dairy foods. She had had paresthesias in legs for 5 years, anorexia and severe pains in legs for 2 years. One and one-half years previously she had stopped work and had entered the hospital for 3 weeks. Diagnosis was "portal cirrhosis and alcoholic neuritis". Four months previously onset of ascites and edema had occurred. Jaundice, nausea and vomiting had been present for 3 months. She re-entered the hospital for 1 month before transfer 
to Research Service. Two abdominal taps were performed. Her best weight was 137; her weight on admission was 119. Chief findings were: jaundice, ascites, edema, palpable liver and spleen, collateral vessels, vascular "spiders", dementia, polyneuritis, glossitis, scaly dry skin and hemorrhoids; RBC 2.7 , Hgb. $51 \%$, WBC 11,000 , serum albumin 2.4 , globulin 3.5 , Takata + , icteric index 35 , bromsulfalein $64 \%$.

The patient received four abdominal taps in 2 months. Thereafter, she showed steady improvement, gained in strength and became mentally lucid. A mild fever subsided after 3 months. There was a gain of weight from 119 to 137 in 9 months without recurrence of ascites. Liver and spleen were smaller but palpable. The "spiders" disappeared. Icteric index was between 5 and 9. She was discharged from the hospital on April 2, 1940 and resumed an active, normal life. On October 23, 1940 (11/3 years after entry) RBC 4.0, Hgb. 96\%, WBC 7,500, serum albumin 4.7, globulin 2.9, Takata negative, bromsulfalein $32 \%$, icteric index 5 . She felt entirely well.

Case 22. A 36-year-old Irish American factory worker entered the hospital on August 7, 1937, because of vomiting blood. She had a history of alcoholism, "chronic indigestion", inadequate diet. Episodes of nausea and vomiting had occurred 2 to 3 times yearly during the previous 7 years. Blood-containing vomitus had been noted on several occasions. She had first entered the hospital June 1937 because of hematemesis and ascites. After two transfusions and one abdominal tap the patient left the hospital; 12 hours later, after another hematemesis, she entered the Research Service. Chief findings were: air hunger, pallor, jaundice, ascites, edema, vascular "spiders", glossitis, palpable liver and spleen, absent ankle jerks; temperature $102^{\circ} \mathrm{F}$., pulse 130 , blood pressure $90 / 50$; RBC 1.78 , Hgb. $31 \%$, WBC 13,000 , serum albumin 1.8, serum globulin 3.5 , Takata + , icteric index 20, bromsulfalein $40 \%$, cholesterol 265 .

The patient was given a glucose infusion followed by transfusion immediately after entry. Temperature ranged from $102^{\circ}$ to $104^{\circ} \mathrm{F}$. for 3 days. For 6 weeks temperature was $100^{\circ} \mathrm{F}$. and thereafter was normal. There was steady improvement for 5 months characterized by gain in strength, disappearance of jaundice, ascites, and edema. On December 3, 1937, laboratory data were: RBC 3.78, Hgb. $79 \%$, WBC 7,700, albumin 4.0, globulin 3.7, icteric index 10 , bromsulfalein $35 \%$, Takata + . The patient felt well, left against advice, and resumed drinking habits. She returned 5 days later in an alcoholic stupor. Shortly after entry she had a massive hematemesis and died. Autopsy showed intestines full of blood. Liver weighed 2,000 grams and was finely nodular. Spleen weighed 340 grams. Histologic section showed portal cirrhosis.

Case 38. A 56-year-old Irish American housewife entered the hospital on March 8,1939, because of vomiting blood. She had a history of alcoholism and poor diet; epilepsy for 35 years. Anorexia and periodic upper abdominal pain had been present for 1 year. Four months previously she had had hematemesis; 3 months previously edema of ankles; 3 weeks previously onset of jaundice; 2 weeks previously hematemesis and onset of ascites. Chief findings were: semi-stupor, fever (laryngitis), jaundice, ascites, edema, palpable liver and spleen, vascular "spiders", collateral vessels, glossitis, polyneuritis, hemorrhoids, incontinence of urine and feces; RBC 2.3, Hgb. $45 \%$, WBC 2,280, serum albumin 2.1, serum globulin 3.9, Takata + , icteric index 35 , bromsulfalein $100 \%$.

Abdominal taps were performed eight times in first 3 months. In the following 3 months diuresis was followed by disappearance of ascites and edema. Her weight fell from 163 to $140 \mathrm{lbs}$. with diuresis. She became mentally clear and gained in strength. Jaundice cleared and vascular "spiders" disappeared. Six months after entry she was ambulatory and strong. She left hospital against advice on September 11, 1939, and was seen in O.P.D. 2 months later. Liver and spleen were palpable. No ascites, edema, or jaundice was present. Laboratory data were: RBC 4.0, Hgb. 75\%, WBC 9,400, serum albumin 4.0 , globulin 3.5 , Takata + , bromsulfalein $53 \%$, icteric index 7. On September 17, 1940, she returned to the clinic (11/2 years after entry to hospital). Except for anemia (hemorrhoidal bleeding), there was no clinical change. Laboratory data were as follows: RBC 2.5, Hgb. 52\%, serum albumin 3.7, globulin 3.4, bromsulfalein $26 \%$, icteric index 5 . She felt well.

Case 23. A 48-year-old Irish housewife entered the hospital April 2, 1937, because of vomiting and abdominal fullness. There was a past history of alcoholism, of 15 pregnancies ( 9 miscarriages) and of a diet very poor in meat and dairy products. Vomiting attacks had been occurring 1 to 2 hours after meals for 1 year. Her weight loss had been $40 \mathrm{lbs}$. in 1 year. She had had abdominal distention for 4 months; ascites for 2 weeks; increasing weakness, dyspnea with exertion. Her best weight had been 150; her recent weight was 92. Chief findings were: pallor, emaciation, mental torpor, nystagmus, glossitis, dry scaly skin, palpable liver and spleen, edema, absent knee and ankle jerks; RBC 1.2, Hgb. 34\%, M.C.V. 154, WBC 3,000, albumin 2.2 , globulin 3.5 , Takata + , bromsulfalein $40 \%$, gastric analysis 0 free $\mathrm{HCl}$, Wassermann + , urine albumin trace, many WBC, NPN 55.

The anemia did not respond to liver therapy. During the first month she had daily vomiting and one hematemesis; the ascites increased. On May 10, 1937, she had transfusion with $500 \mathrm{cc}$. blood. Improvement followed with a gain in weight and strength. Vomiting ceased; diuresis with loss of ascites occurred after 6 weeks; the liver edge receded. She became mentally clear and felt well. She was discharged against advice on October 6, 1937, 6 months after entry. At this time laboratory data were: RBC 2.86, $\mathrm{Hgb}$. $58 \%$, WBC 5,000, serum albumin 3.7, globulin 3.0, Takata negative, icteric index 4, bromsulfalein $10 \%$. Urine showed albumin and many WBC, NPN 74 (at entry 55). She was readmitted 4 months later (February 5,1938 ) because of vomiting and nose bleeds. Chief findings were: pallor, stupor, palpable liver and spleen, blood pressure $170 / 120$, pericardial rub; 
P.S.P. test $1 \%$ in 2 hours, NPN 400 , urine as before, no ascites, no jaundice. The patient died in uremia after 1 week. Autopsy showed pyelonephritis; cirrhosis of the liver (slight fibrosis).

Case 41. A 55-year-old American salesman entered the hospital on December 28, 1937, because of abdominal swelling. He had a history of alcoholism. His diet had been poor in meat and dairy products. He had periodic nausea and diarrhea. Twelve years previously he had been hospitalized for 3 months because of hypertensive heart disease. Two years before admission he had been hospitalized for 2 months because of jaundice and edema; there had been a question of ascites. At that time the blood pressure was $180 / 100$; liver was palpable; urine showed RBC, WBC, albumin, granular casts. On admission chief findings were: palpable liver and spleen, ascites, edema, vascular "spiders", glossitis, neuritis; RBC 4.4, Hgb. 98\%, WBC 7,000, Takata \pm , serum albumin 2.7 , serum globulin 4.7 , icteric index 5 , bromsulfalein $40 \%$, venous pressure 90 , circulation time 12 seconds (decholin). Urine showed RBC, WBC, albumin and occasional casts; PSP test $80 \%$, concentration up to 1020.

One abdominal tap was performed. Diuresis with loss of ascites occurred in 1 month. His weight fell from 268 to $212 \mathrm{lbs}$. There was no recurrence of ascites, edema, or jaundice. Liver remained palpable. There was steady gain in strength. Blood pressure was variable between $140 / 90$ and 190/100. During the last 6 months of his hospital stay he received 9 ounces of $40 \%$ alcohol daily with no untoward effects. He was discharged on June 5, 1939, 11/2 years after entry. At this time laboratory data were: RBC 5.3, Hgb. $105 \%$, WBC 6,500 , albumin 3.7 , globulin 3.3 , bromsulfalein $28 \%$, icteric index 2, Takata negative. In O.P.D. on March 5, 1940, blood counts and urinary sediment were the same as before; serum albumin 4.4, globulin 2.8. The patient was active as salesman. On September 7, 1940 (31/2 years after entry), findings were essentially unchanged; he felt well.

Case 25. A 46-year-old American seaman entered the hospital on November 16,1937, because of vomiting. There was a history of typhoid 40 years before, of alcoholism for 25 years, and of a diet poor in meat and vegetables. Seventeen years previously a chancre had been treated with one course each of arsphenamine and tryparsamide. Nausea, vomiting, and abdominal distress had been present 10 years. Signs of tabes dorsalis were recognized for 7 years. Periodic edema of ankles had occurred for 4 years; severe nausea and vomiting for 2 weeks, followed by onset of jaundice, ascites, and edema. His best weight had been 149; his weight on admission was 117. Chief findings were: emaciation, jaundice, irregular fixed pupils, palpable liver and spleen, ascites, edema, tremor, absent knee jerks and ankle jerks, Romberg + , hemorrhoids, blood pressure 120/78; RBC 4.4, Hgb. 95\%, WBC 5,800, Takata + , serum albumin 3.0, globulin 3.6, icteric index 15 , bromsulfalein $45 \%$, blood Wassermann + , spinal fluid negative.

Ascites formation increased 3 weeks after entry with a gain in weight from 124 to 156 lbs. Dietary therapy and four injections of mercupurin were given. After 3 weeks diuresis with loss of ascites and edema occurred. There was no recurrence during next $11 / 2$ years. He gained in weight and strength. He had occasional "gastric crises" and "shooting pains" and a sudden hemiplegia on April 12, 1939. Blood pressure was 160/110; spinal fluid was bloody. $\mathrm{He}$ had a terminal bronchopneumonia and died May 4, 1939, 16 months after entry. Laboratory data on January 15, 1939 (14 months after entry) were: RBC 4.4, Hgb. 85\%, WBC 9,400, serum albumin 4.8, globulin 2.1, Takata negative, bromsulfalein $8 \%$, icteric index 4 . With terminal illness, 3 months later, there was a rise in icteric index to 14 and in bromsulfalein to $44 \%$. Autopsy showed tabes dorsalis, bronchopneumonia, cirrhosis of liver (minimal fibrosis). Autopsy on head was not granted.

Case 30. A 63-year-old French chef entered the hospital May 9, 1938, because of dyspnea and recurrent ascites. Past history was irrelevant. Right upper quadrant pain, headaches and dyspnea had been present for 4 years. Increasing dyspnea, palpitation and weakness had been present for 3 years. One year previously he had entered the hospital for 1 month. The diagnosis was hypertensive heart disease and enlarged liver. Blood pressure was 200/100. He had slight ankle edema. Onset of ascites had occurred 3 months before present admission. Two months previously he had entered another hospital. He vomited blood for a day after entry. $\mathrm{X}$-ray showed esophageal varices. Digitalis and mercupurin were administered. Abdominal taps were performed weekly for 7 weeks. His weight loss had been 40 lbs. in 2 years. On transfer to Research Service, chief findings were: emaciation, dyspnea, cardiac enlargement, blood pressure $200 / 100$, ascites, slight peripheral edema, palpable, non-tender liver and spleen, pigmentation, diminished vibratory sensation in legs; RBC 3.6, Hgb. $68 \%$, WBC 8,800, Takata + , icteric index 3, bromsulfalein $18 \%$, albumin 3.2 , globulin 3.2 ; urine showed albumin + and many WBC. Right pyelogram showed hydronephrosis; venous pressure was 70 , circulation time was 16 seconds (decholin).

$\mathrm{He}$ was maintained on digitalis, grains $11 / 2$ daily. He had six abdominal taps in the first 3 months and none thereafter for 2 years. Digitalis was withheld for 1 month on 3 occasions. Venous pressure rose to $150 \mathrm{~mm}$., $\mathrm{H}_{2} \mathrm{O}$ and circulation time to 20 seconds without return of ascites or edema. It was therefore believed that this was not a case of cardiac cirrhosis. Pyuria cleared with mandalate therapy. The patient became ambulatory and well. On May 2, 1940, laboratory data were: RBC 4.2, Hgb. 82\%, WBC 6,000, albumin 4.3, globulin 3.5, Takata negative, bromsulfalein $20 \%$. He was readmitted on July 13,1940, with signs attributable to abdominal malignancy. There was no sign of heart failure and no return of ascites. He died on August 19, 1940. There was no autopsy.

Case 43. A 61-year-old Irish bartender entered the hospital January 7,1938 , because of abdominal swelling. There was a history of typhoid fever and malaria in 
childhood, of gonorrhea 40 years before hospital entry, and of alcoholism for 25 years. Hemorrhoids were present for 6 years. Massive hematemesis, followed by intermittent abdominal distention, occurred 4 years before admission. A massive hematemesis occurred 3 years before, which necessitated a blood transfusion. Icterus was noted. He had cramps and paresthesias in legs for 1 year. For 4 months there had been anorexia and increasing abdominal fullness. For 2 months he had noticed swelling of ankles and feet and had felt weak. His average weight was 180 . Chief findings were: ascites, edema, palpable liver and spleen, vascular "spiders", collateral veins, pigmentation, umbilical hernia, polyneuritis, mental confusion, glossitis, hemorrhoids, urethral stricture; RBC 4.3, Hgb. 92\%, WBC 2,800, Takata +, icteric index 5 , bromsulfalein $40 \%$, serum albumin 3.2 , serum globulin 3.5 .

Fifteen abdominal taps were performed in 10 months with time intervals between taps gradually lengthening. During the next 4 months there was no recurrence of ascites or edema. Liver and spleen were barely palpable. He had surgical repair of strangulated umbilical hernia on January 12, 1939, without ill effect. He was discharged April 15, 1939 and resumed work. $\mathrm{He}$ had a repair of the urethral stricture on May 20, 1939. On follow-up August 21, 1940 (21/2 years after entry), there was no clinical change. Laboratory data at this time were: RBC 4.6, Hgb. $90 \%$, WBC 3,500, albumin 4.7, globulin 2.7, Takata negative, bromsulfalein $18 \%$, icteric index 5. He felt well and was active as bartender.

Case 47. A 45-year-old Irish bartender's wife entered the hospital October 5, 1936, because of swollen abdomen. She had a history of "moderate" alcohol intake. Anorexia, nausea and vomiting, followed by onset of ascites and hematemesis, had occurred $11 / 2$ years before admission. She was hospitalized for 6 months and received mercurial diuretics and four abdominal taps. Three days after discharge she entered another hospital because of hematemesis. She had nine abdominal taps in the next 4 months and was transferred to Research Service on October 5, 1936. Chief findings were: emaciation, dry scaly skin, glossitis, vascular "spiders", collateral circulation, ascites, edema, palpable liver and spleen, clubbed fingers, right hydrothorax, net weight 93 lbs.; RBC 4.0, Hgb. $81 \%$, WBC 7,500, serum albumin 2.2, globulin 2.8 , bromsulfalein $24 \%$, Takata + , icteric index 8.

The patient's condition was critical during the first 6 weeks. Two abdominal taps were performed. Thereafter, gradual diuresis with loss of ascites and edema occurred, followed by disappearance of vascular "spiders" and clubbing. Liver and spleen were smaller but still palpable. She showed striking gain in weight and strength and was ambulatory after 11 months. Her weight was 145 lbs. She was discharged January 18, 1938, 15 months after entry, and resumed housework. On August 23, 1940 (4 years after entry) the liver and spleen were still palpable, weight was 145 lbs.; RBC 4.5, Hgb. $88 \%$, WBC 5,500, albumin 4.9, globulin 3.1, icteric index 5 , bromsulfalein $20 \%$, Takata negative. She felt entirely well.

Case 46. A 63-year-old Irish laborer entered the hospital July 4, 1936, on account of abdominal swelling. He was an alcoholic and his diet had been poor in meat and dairy products. For 5 years nausea and vomiting had occurred after drinking liquor. For 1 year he had had intermittent edema of ankles. For 3 months he had had progressive swelling of the legs, scrotum, abdomen, and transient jaundice. Chief findings were: undernutrition, ascites, edema, palpable liver, collateral veins, glossitis, polyneuritis, hemorrhoids; RBC 4.6, $\mathrm{Hgb}$. $99 \%$, WBC 12,000 , albumin 2.2, globulin 3.6, icteric index 4 , bromsulfalein $25 \%$, Takata + .

Four abdominal taps were performed in 2 months. He had a sudden diuresis followed by loss of ascites and edema. His weight fell from 160 to $120 \mathrm{lbs}$. in 3 weeks. Thereafter he showed a steady gain in weight and strength. The liver edge receded. The patient felt well and resumed former work. At the time of discharge on February 15, 1938, his weight was 145 lbs., RBC 4.8, Hgb. 95\%, WBC 7,000, serum albumin 5.0, globulin 3.8, bromsulfalein $20 \%$, Takata \pm , icteric index 5 . He returned to follow-up 10 months later (December 2, 1938) because of paresthesias in legs. There was no return of ascites or edema; liver was barely palpable; polyneuritis was marked. Vitamin therapy was resumed, together with 9 ounces of $40 \%$ alcohol daily for the ensuing 14 months. There was no essential change. The patient was ambulatory and well. On October 1, 1940 (4 years after first entry) laboratory data were as follows: RBC 4.3, Hgb. $84 \%$, WBC 9,000, albumin 4.5, globulin 2.7, icteric index 7 , bromsulfalein $25 \%$, Takata negative.

Case 42. A 57-year-old Russian sailor entered the hospital January 14, 1938, because of abdominal swelling. He was an alcoholic and his diet had been poor in meat and vegetables. He had had hemorrhoids 2 years before admission. Onset of jaundice, ascites and edema had occurred 31/2 months before admission. He had been hospitalized October 18, 1937, for 3 weeks. Examination showed above signs and an icteric index of 45 . He had diuresis with mercurial drug. His weight fell from 205 to 173 lbs. He was readmitted on December 13, 1937, with identical signs. His icteric index was 18 . He received an abdominal tap and mercurial diuretics and was transferred to Research Service. Chief findings were: ascites, edema, palpable liver and spleen, collateral veins, hemorrhoids, glossitis, polyneuritis; RBC 3.1, Hgb. $76 \%$, WBC 4,500 , serum albumin 2.8 , globulin 4.5 , icteric index 7 , Takata + , bromsulfalein $40 \%$, urine negative.

There was loss of ascites and edema during the first month and gain in strength. On February 15, 1938, he had an upper respiratory infection followed in 3 weeks by signs of acute nephritis with anasarca. Urine showed albumin, RBC's and casts. Blood pressure rose from $130 / 75$ to $160 / 100$; N.P.N. from 30 to 65 ; weight increased from 157 to $187 \mathrm{lbs}$. (anasarca); serum albumin fell from 3.1 to 2.0. Steady clinical improvement took place in 6 weeks with loss of ascites and edema. At dis- 
charge, January 19, 1939 (1 year after entry), the laboratory data were: RBC 4.0, Hgb. $90 \%$, WBC 4,100, albumin 3.8, globulin 3.0, bromsulfalein $30 \%$, Takata negative, icteric index 7. He resumed work. He was readmitted April 14, 1939, with a transient jaundice after an upper respiratory infection. It subsided in 1 week and he resumed work. He was readmitted May 28, 1940, for study. He felt entirely well. Liver was not palpable; spleen was palpable; weight was 178 . There was no ascites, edema, or jaundice and no change in laboratory data. On September 7, 1940 ( 2 years and 9 months after entry) there was no essential change.

Case 45. A 40-year-old negro painter entered the hospital January 26, 1937, because of jaundice and swollen abdomen. He had a history of alcoholism, chancre 15 years before, poor diet. One year previously he had entered the hospital for 6 months because of jaundice, edema and dyspnea. After discharge he resumed old habits. He had had increasing ascites, jaundice, abdominal pain, nausea and vomiting for 1 month before admission. $\mathrm{He}$ had had epistaxis 1 day. He entered the hospital December 16, 1936 and had an abdominal tap on the day of entry. Ascites returned. He had diuresis after 1 month with KI, saline and mercurial diuretics. On transfer to Research Service, the chief findings were: jaundice, vascular "spiders", palpable liver and spleen; RBC 3.9, Hgb. $76 \%$, WBC 6,200 , Wassermann $2+$, serum albumin 3.6, globulin 3.8, icteric index 33, Takata + . No ascites or edema was present.

The patient had a chill and fever for 2 days. Temperature was 100 to 101 for 1 week; thereafter it ran a benign course. The liver edge receded. There was no return of ascites or edema. Jaundice disappeared. The patient was discharged after 8 months (October 9, 1937) with RBC 4.6, Hgb. 99\%, WBC 6,200, albumin 3.9, globulin 2.7 , icteric index 8 , bromsulfalein $36 \%$, Takata negative. He felt entirely well. $\mathrm{He}$ was symptom-free for $3 \frac{1}{2}$ years, then resumed previous drinking habits and was readmitted to the hospital in May 1940 with ascites and jaundice.

Case 48. A 49-year-old Irish American clerk entered the hospital November 27, 1936, because of swollen legs. She gave a history of chronic alcoholism and poor diet. Five years previously she had been hospitalized for syphilis, pulmonary tuberculosis and multiple neuritis. She received 15 injections of neoarsphenamine; her Wassermann became negative. The infiltration at the right lung apex healed. Biceps, triceps, Achilles reflexes remained absent. Paresthesias disappeared. Liver and spleen were not palpable. She was discharged July 28, 1932, 10 months after entry. In the interval before she re-entered the hospital alcoholism was severe and neuritis recurred. One month before re-entry she had transient jaundice and edema of legs. Chief findings were: obese woman, mentally dull and confused; tremor of hands, pellagrous dermatitis, glossitis, umbilical hernia, palpable spleen and liver, vascular "spiders", polyneuritis, phlebitis; RBC 3.5, Hgb. 88\%, WBC 6,500, serum albumin 4.2, globulin 4.5, Takata + , bromsulfalein $10 \%$, icteric index 3 . No ascites or jaundice.
Jaundice cleared before entry. With therapy, there was marked improvement in psyche and sensory components of neuritis. The liver receded in size; the spleen was still palpable. Laboratory data on discharge were: bromsulfalein 0 , albumin 4.5 , globulin 3.1 , Takata negative. Other laboratory data were unchanged. She was discharged April 1, 1937, 4 months after entry, and resumed work. There was no follow up.

Case 49. A 48-year-old American housewife entered the hospital March 13, 1937, because of jaundice. She gave a history of alcoholism and poor diet. Four years previously she had been jaundiced for several months. For 2 years she had been on a liquid diet and for 6 months she had had dysphagia and regurgitation of foods. She had been bedridden for 4 months because of weakness and paralysis. Jaundice recurred 1 month before admission. Chief findings were: Obese, jaundiced woman, dull, confused, disoriented; nystagmus, pellagrous dermatitis, glossitis, severe polyneuritis, vascular "spiders", palpable liver; RBC 3.46, Hgb. 77\%, WBC 7,000, serum albumin 3.7, globulin 3.6, Takata negative, bromsulfalein $>40$, icteric index 30 . There was questionable ascites and splenomegaly.

The patient was fed by nasal catheter for 1 month and thereafter ate solid foods. She showed marked improvement in strength and psyche. There was a subsidence of neuritis, dermatitis and glossitis; the liver edge receded, the jaundice disappeared after 1 month. The patient became ambulatory but had a residual foot drop. She was discharged December 23, 1937, 7 months after entry. Laboratory data were: RBC 4.2, Hgb. $91 \%$, WBC 6,000, icteric index 3 , bromsulfalein $20 \%$, albumin 4.9 , globulin 2.8, Takata negative. On June 25, 1940, the patient was ambulatory and well. Laboratory data were essentially unchanged $31 / 2$ years after entry.

Case 50. A 49-year-old Irish American housewife entered the hospital November 1, 1938, because of weakness. She was a chronic alcoholic whose diet had been poor in meat and dairy foods. Nausea, vomiting, abdominal cramps had occurred for several years. One year previously she received 24 injections of neoarsphenamine. For 10 months there had been six loose stools daily, and for 1 month vomiting spells, inability to walk, and paresthesias of the legs were noted. Her best weight was 145; her weight on admission was 128 . Chief findings were: mental torpor and confusion, nystagmus, polyneuritis, rough dry skin, vascular "spiders", palpable liver, collateral veins, glossitis, hemorrhoids; RBC 4.8, Hgb. $85 \%$, WBC 5,000, serum albumin 3.6, globulin 3.6, Takata + , bromsulfalein $20 \%$, icteric index 5 . No jaundice or ascites was present.

The patient gained in weight and strength; the liver edge receded; the "spiders" disappeared. She had no G.I. disturbances. The neuritis was only partially improved. She was discharged on March 15, 1940 and resumed work. On discharge laboratory data were: RBC 4.5, Hgb. $96 \%$, WBC 11,000 , serum albumin 5.1, globulin 2.9, Takata negative, icteric index 5 , bromsulfalein 0 . On October 1, 1940, 2 years after entry, there was no clinical change. She felt well. 
Case 51. A 53-year-old Irish American clerk entered the hospital October 19,1939, because of numbness of legs. He gave a history of alcoholism and poor diet. He had been hospitalized February 1, 1939, because of optic neuritis. Chief findings were: optic atrophy, polyneuritis, palpable liver and spleen, collateral veins, glossitis; bromsulfalein $30 \%$, albumin 4.3 , globulin $3.3, \mathrm{Ta}-$ kata negative. There was no ascites. The patient was seen periodically in O.P.D. and was admitted to Research Service because of paresthesias in legs. Added to the above findings were icterus and vascular "spiders", RBC 4.6, Hgb. $86 \%$, WBC 6,700 , albumin 4.5 , globulin 3.3, bromsulfalein $40 \%$, icteric index 15 , Takata negative.

The patient was placed on dietary therapy and was given 9 ounces of $40 \%$ alcohol daily during 6 months' stay. He showed steady gain in weight and strength. Liver and spleen remained palpable. Neuritis subsided. Vascular "spiders" disappeared. On discharge laboratory data were: RBC 4.8, Hgb. $90 \%$, WBC 3,500, albumin 5.1, globulin 2.7, icteric index 7 , bromsulfalein $16 \%$, Takata negative. On October 1, 1940, 1 year after entry, there was no clinical change.

Case 52. A 26-year-old Irish American typist entered the hospital December 11, 1937, because of a mass in the abdomen. She gave a history of alcoholism and poor diet. She had had anorexia for 3 years, nausea and vomiting for 2 years, and a mass in the abdomen and edema of ankles, followed by severe epigastric pain and jaundice, 2 months before admission to the hospital. She was hospitalized November 4, 1937. In the hospital she had a hematemesis and epistaxes. Her icteric index was 16. Exploratory laparotomy revealed large, granular liver. Biopsy showed fatty degeneration and periportal fibrosis. Severe paresthesias of legs developed postoperatively. After 5 weeks patient signed release; she entered Research Service 2 weeks later. Her weight 8 years previously had been $127 ; 3$ years previously 110 ; 1 month previously 80 lbs. Chief findings were: Emaciated, pale, hysterical young woman; dry, parchment-like skin, vascular "spiders", hard, tender liver filling right half of abdomen, palpable spleen, collateral veins, glossitis, polyneuritis, hemorrhoids; RBC 3.3, Hgb. $71 \%$, WBC 7,250 , Takata + , icteric index 2 , bromsulfalein $5 \%$, serum albumin 3.9 , globulin 4.7 . No ascites.

In July 1938, the patient had an episode of fever, chills, colon bacilluria due to left ureteral stone; symptoms subsided with passage of stone. In September 1938, she had transient jaundice for 2 weeks; no apparent cause. (Icteric index rose to 25.) Except for these 2 complications, she showed steady improvement. There were no G.I. disturbances; the liver edge receded; vascular "spiders" disappeared; neuritis subsided. The patient resumed work on December 5, 1938, 1 year after entry. She was seen periodically in O.P.D. and felt entirely well. Her weight was $123 \mathrm{lbs}$, the liver edge was at the costal border. On June 4, 1940, laboratory data were: RBC 4.5, Hgb. $85 \%$, WBC 7,000, icteric index 5, bromsulfalein $10 \%$, albumin 5.4 , globulin 3.1 , Takata negative. On September 7, 1940 (2 years, 9 months after entry), there was no clinical change.
Case 44. A 45-year-old Irish cook entered the hospital April 28, 1937, because of painful, weak legs. She gave a history of alcoholism and a diet poor in meat and vegetables. She had had a daily purgation with epsom salts for the previous 4 years. Her weight had fallen from 150 to $94 \mathrm{lbs}$. She had been hospitalized 5 years previously for alcoholism. She had had progressive weakness and paresthesias of legs for 5 months; dysphagia, incontinence of urine and feces for 3 months; persistent vomiting for 2 months. She was hospitalized March 31, 1937, and transferred to Research Service 1 month later. Chief findings were: pale emaciated, disoriented; skin rough, dry, and pigmented; vascular "spiders", palpable liver, ascites, glossitis, collateral veins, severe polyneuritis; RBC 3.7, Hgb. $81 \%$, WBC 10,000 , serum albumin 3.8, globulin 2.7 , bromsulfalein $20 \%$, Takata negative, icteric index 3. She had no jaundice.

Except for transient phlebitis of leg, improvement was steady. There was no recurrence of ascites; the liver edge receded; glossitis and polyneuritis subsided. Her weight rose to $140 \mathrm{lbs}$. In addition to dietary therapy, the patient received 9 ounces $40 \%$ alcohol daily for $11 / 2$ years without causing apparent change. She was discharged September 1, 1939, to resume work and was seen periodically in O.P.D. Laboratory data on May 18, 1940 were: RBC 5.0, Hgb. 95\%, WBC 7,450, serum albumin 5.0, globulin 2.5, Takata negative, bromsulfalein $30 \%$, icteric index 7 . She felt entirely well 3 years after entry.

\section{Group 2}

Case 26. A 40-year-old Italian barber entered the hospital January 7, 1938, because of swelling of legs and abdomen. There was a past history of chronic alcoholism. He had had varicose veins 15 years previously and intermittent swelling of legs for 10 years. He had had phlebitis 3 years previously. Previous hospital admissions: (1) March, 1934 : Edema, hematuria, albuminuria, palpable liver, B.P. 165/100. Diagnosis: nephritis; cirrhosis of liver. (2) July, 1935: Palpable liver and spleen, jaundice, clubbed fingers. (3) November, 1935 : Palpable liver and spleen, jaundice, ascites. Urine negative. Loss of ascites with mercurial diuretics. (4) April, 1936: Ascites, edema, palpable liver and spleen, jaundice (icteric index 40), phlebitis. (5) November, 1938: Above findings. Diuresis with mercurial diuretics. Weight fell from 280 to $230 \mathrm{lbs}$. Transferred to Research Service. Chief findings were: Obese Italian; jaundice, vascular "spiders", palpable liver and spleen, ascites, umbilical hernia, thrombophlebitis of legs, clubbed fingers; RBC 4.8, Hgb. 84\%, WBC 3,400, bromsulfalein $>40 \%$, icteric index 20 , Takata + , serum albumin 2.4 , globulin 4.8 .

His chief disability was recurrent phlebitis; he had nine episodes with chill, fever, and painful swelling of legs; he had frequent hemoptyses. On at least two occasions he had a pulmonary infarction. Otherwise the patient felt well during his 18 months' stay. Ascites disappeared without recurrence. His weight fell from 230 to 210 ; albumin rose to 3.0 , globulin fell to 3.8 ; 
icteric index 10 to 15 . There were no other changes and his course was considered stationary. He was discharged July 19, 1939, and died suddenly at another hospital 4 months later. There was question of a pulmonary embolus. There was no autopsy.

Case 27. A 49-year-old Italian laborer entered the hospital January 1, 1938, for abdominal swelling. He gave a history of alcoholism and poor diet; he had had syphilis and arsphenamine therapy 25 years previously. Previous hospital admissions: June, 1934: Jaundice, ascites; abdominal tap. April, 1935: Ascites, edema, palpable liver, hematemesis; abdominal tap. June, 1935 : Ascites, edema, palpable liver and spleen, jaundice, glossitis, vascular "spiders"; abdominal tap. September, 1937: Signs and therapy as above. November, 1937: Above signs, vomiting, melena; icteric index 25 . Between hospital entries, the patient received injections of mercurial diuretics 2 to 3 times weekly to control ascites. He entered Research Service on January 1, 1938. Chief findings were: Icterus, nystagmus, ascites, edema, vascular "spiders", pigmentation, glossitis, palpable liver and spleen; RBC 4.2, Hgb. $88 \%$, WBC 7,200, albumin 3.2, globulin 4.0, icteric index 10, bromsulfalein $>40$, Takata + ; occasional RBC, WBC, casts and + albumin in urine. There was a question of polyneuritis.

The patient had four abdominal taps in 3 months; thereafter he was ambulatory and ascites-free for $11 / 2$ years without taps or diuretics. Takata was negative. In September, 1939 he had a sudden chill, fever and signs of pneumonia, with rapid onset of ascites. He had weekly abdominal taps until death, 7 months later. Albumin declined 3.6 to 2.8 ; icteric index rose from 6 to 15 ; bromsulfalein rose from 40 to $80 \%$; spleen was enormous, Takata $t$. He died April 25, 1940, 21/3 years after entry. Portal thrombosis was suspected. There was no autopsy.

Case 29. A 53-year-old American janitor entered the hospital December 21, 1937, because of abdominal swelling. He gave a history of alcoholism and a diet poor in meat and vegetables. His Wassermann had been positive in 1931. He had had arsphenamine therapy in 1931 and 1932. He had had paresthesias in legs for several years, intermittent swelling of legs and abdomen for one year and persistent swelling for 2 months. He was hospitalized on November 29, 1937 and had an abdominal tap. His weight fell from 174 to $148 \mathrm{lbs}$. He received diuretics and minimal vitamin therapy. Ascites recurred in 3 weeks and he was transferred to Research Service. Chief findings were: Dry, rough skin, polyneuritis, glossitis, vascular “ spiders", palpable liver and spleen, ascites, collateral veins; $\mathrm{RBC} 3.8, \mathrm{Hgb}$. $75 \%$, WBC 8,000, serum albumin 2.5 , globulin 3.4 , bromsulfalein $28 \%$, Takata + , icteric index 5 .

He was given intensive vitamin therapy at entry and had diuresis in 5 days. His weight fell from 165 to 130 lbs., with loss of ascites and edema. Albumin rose from 2.5 to 3.2 in 10 days. For the next 2 years the patient was ambulatory and well. His weight rose from 130 to 150 lbs. He had no G.I. disturbances; no ascites or edema. Laboratory data, however, remained un- changed: Serum albumin 3.1 to 3.5 , icteric index 5 to 12 , bromsulfalein 15 to $40 \%$, Takata $2+$ to 4 , globulin 3.5 to 4.0. He was discharged February 6, 1940, and returned 1 month later with massive ascites. He was mentally confused (interval history unreliable). Laboratory data were: Serum albumin 2.4, globulin 3.4, RBC 4.7, Hgb. $90 \%$, WBC 13,500. There was rapid onset of coma, with death 4 days after entry. Autopsy showed portal cirrhosis of liver.

Case 28. An 83-year-old Italian laborer entered the hospital September 16, 1937, for abdominal swelling. He gave a history of alcoholism, syphilis and poor diet (0 meat, 0 vegetables). He had had a course of arsphenamine 5 years previously. Anorexia and abdominal swelling had been present for 1 year. He entered the hospital in January 1937. Chief findings were: Ascites, edema, hydrothorax; icteric index 18, bromsulfalein $50 \%$, Wassermann negative. He received three abdominal taps and mercurial diuretics; was transferred to Research Service September 16, 1937. Chief findings were: Emaciated old man; dry, rough skin, pigmentation, glossitis, collateral veins, ascites, edema, B.P. 135/75; RBC 3.7, $\mathrm{Hgb}$. 75\%, WBC 7,800, serum albumin 1.8, globulin 5.3, Takata + , icteric index 9, bromsulfalein $>40$; Wassermann negative. There was a question of peripheral neuritis. Liver and spleen were not felt.

He had two abdominal taps in 2 months. Mercupurin injections at intervals controlled minimal ascites and edema for 8 months. After 1 year no ascites or edema was present. Serum albumin in 1 year rose from 1.8 to 3.0 ; globulin varied from 4.6 to 5.6 ; Takata remained + ; icteric index rose from 5 to 10 ; bromsulfalein was \pm 40 . Weight was between 120 and $125 \mathrm{lbs}$. His course was stationary throughout the second year. There was no ascites. The patient was ambulatory. Laboratory values remained unchanged. In September 1939, 2 years after entry, there was increasing jaundice. The icteric index rose gradually to 50 in November; albumin fell from 3.0 to 2.1. Hgb. fell from 80 to $67 \%$. The patient lapsed into coma and died on January 23, 1940, 2 years and 4 months after entry. Autopsy showed carcinoma of caudate lobe, cirrhosis (portal) of liver. The terminal 4-month course was probably due to the superimposed carcinoma.

Case 35. A 38-year-old Porto Rican entered the hospital November 15, 1938, because of swollen abdomen. She gave a history of alcoholism and poor diet ( 0 meat; 0 vegetables). She had had rheumatic fever 10 years previously and a hysterectomy 5 years previously. She had had recurrent epistaxes for 4 years, occasional tarry stools for 3 years, purpuric spots and easy bruising for 2 years, intermittent jaundice for 2 years. She had lost $17 \mathrm{lbs}$. in 1 year, had had paresthesias for 1 year and swelling of abdomen and ankles for 8 months. She entered another hospital 2 months before being transferred to Research Service. Chief findings were: Jaundice, ascites, edema, palpable liver and spleen, collateral veins, vascular "spiders", mitral valvulitis; $R B C$ 2.2, $\mathrm{Hgb}$. $48 \%$, WBC 5,300 , platelets 80,000 , icteric index 20 , cholesterol 485 , Takata + , trace of bile in urine. 
Stools were negative for schistasoma. She received a high $\mathrm{CHO}$ diet and vitamin supplements. When transferred to Research Service, findings were as above. In addition, glossitis, mild peripheral neuritis, nystagmus and pigmentation over tibiae were present. On November 7, 1938, laboratory data were: $\mathrm{RBC} 2.34$, Hgb. $59 \%$, WBC 8,000 , Wassermann $2+$, albumin 2.9 , globulin 4.5, Takata + , icteric index 50 , bromsulfalein $80 \%$, trace of bile in urine.

Ascites increased in the first 2 weeks after hemorrhage from vascular "spider" on lip; bleeding point was cauterized; patient was transfused with $400 \mathrm{cc}$. blood. Diuresis was followed by a $20 \mathrm{lb}$. weight loss and disappearance of ascites and edema during the next 2 months. The patient showed a marked gain in strength, felt well and left against advice. On discharge, 4 months after entry, laboratory data were: RBC 3.0, Hgb. $69 \%$, WBC 6,800 , icteric index 20 , albumin 3.4 , globulin 4.1, Takata + , bromsulfalein $70 \%$. She entered another hospital 1 month later because of massive hematemesis and was transfused. Liver biopsy showed portal cirrhosis. She was discharged after 1 month and seen at home July 9, 1939, when she was ambulatory but weak. She had slight jaundice, albumin 3.7 and globulin 4.6. There was no ascites. She returned to Puerto Rico and there was no follow up.

Case 39. A 58-year-old Swedish watchmaker entered the hospital May 24, 1939, because of swollen abdomen. He gave a history of alcoholism, inadequate diet, occasional diarrhea and cramps in fingers and toes. He had had daily epistaxes for 6 months and ascites for 1 month. He was hospitalized May 4, 1939. There was partial loss of ascites with mercurial diuretics and minimal vitamin therapy. His weight fell from 176 to 165 . He was transferred to Research Service 3 weeks later. Chief findings were: dry, rough skin, jaundice, vascular "spiders", pigmentation, collateral veins, palpable liver and spleen, ascites, edema, peripheral neuritis; RBC 3.1, Hgb. $65 \%$, WBC 7,600 , icteric index 25 , bromsulfalein $86 \%$, albumin 2.9 , globulin 5.7 , Takata + .

Diuresis continued after entry. He received a nutritious diet without vitamin supplements and felt moderately well. His icteric index fell to 8 ; bromsulfalein to $68 \%$. Blood counts and serum proteins remained unchanged. He was discharged August 12, 1939, and followed in O.P.D. Although there was no recurrence of ascites, the patient felt poorly and complained of fatigue. Mild icterus was consistently present (icteric index 20 to 40 ). He was re-admitted on December 18, 1939 and a nutritious diet and vitamin $\mathrm{B}$ concentrates were given. His weight increased $20 \mathrm{lbs}$. in 4 months. There was no ascites. Polyneuritis and jaundice subsided. He was discharged on May 24, 1940, and followed in O.P.D. On November 16, 1940, laboratory data were: albumin 4.0, globulin 4.3 , icteric index 12 , bromsulfalein $72 \%$. The patient felt much improved $1 \frac{1}{2}$ years after first entry.

Case 40. A 50-year-old Greek clerk entered the hospital January 12, 1939, because of abdominal swelling. He gave a history of alcoholism. His diet had been adequate. He had no history of malaria. Three years previously (November, 1935) he had had swelling of abdomen and legs and had been hospitalized for 7 weeks. One abdominal tap had been performed. He was readmitted 4 times at monthly intervals for abdominal taps. Since July, 1936, the ascites had been partially controlled by weekly injections of mercurial diuretics and daily ingestion of saline diuretics. He was never ascites-free. One year before admission to Research Service he had had a transient hemiplegia. For 1 year he had had paresthesias in legs. He reentered the hospital because of failure of the ascites to respond to diuretics and was transferred to Research Service January 12, 1939. Chief findings were: hepatic facies, vascular "spiders", increased pigmentation, B.P. 180/110, umbilical and inguinal herniae, collateral veins, ascites, palpable liver and spleen, hemorrhoids, edema; venous pressure 94 , circulation time 14 seconds, RBC 4.2, Hgb. 92\%, WBC 4,500 , albumin, RBC's and casts in urine, bromsulfalein $30 \%$, Takata + , serum albumin 2.7 , globulin 3.3 , icteric index 3. There was no cardiac enlargement.

One abdominal tap was performed 2 weeks after entry. Saline diuretics were given for 6 months. There was a gradual disappearance of ascites and edema and the patient was free of ascites and edema for 1 year. Liver and spleen were barely palpable. Vascular "spiders" disappeared. Hypertension and urinary changes persisted. Pyelogram showed destructive lesion in the kidney pelvis. Guinea pig showed + Tbc. He was discharged against advice on July 1, 1940, $11 / 2$ years after entry. Laboratory data were: RBC 4.2, Hgb. $88 \%$, WBC 5,200 , bromsulfalein $14 \%$, icteric index 5 , serum albumin 3.0 , globulin 2.8, Takata negative. The patient was ambulatory but not strong. When he was seen 2 months later, the ascites was returning.

Case 32. A 45-year-old Greek waiter entered the hospital March 13, 1940, because of hematemesis. He had had three courses of arsphenamine therapy 15 years previously and 3 injections yearly thereafter. His diet had been poor in meats and fats. He did not take alcohol. He had had G.I. distress for many years and had taken cathartics daily for 5 years for constipation and hemorrhoids. For $1 \frac{1}{2}$ years he had had severe epigastric pain 1 to 2 hours after meals. Tarry stools had been noted. In February, 1940, he had had two massive hematemeses followed by onset of ascites. $\mathrm{He}$ was hospitalized. Fluoroscopy showed esophageal varices. He was transferred 1 month later to Research Service. Chief findings were: Pallor, vascular "spiders", palpable liver and spleen, ascites, collateral veins; RBC $3.34, \mathrm{Hgb} .53 \%$, WBC 3,450 , Takata + , bromsulfalein $30 \%$, serum albumin 3.2, globulin 3.1, icteric index 7. There was no jaundice.

Two months after entry he had a sudden melena for which there was no apparent cause. After that, the patient made steady gain in weight and strength. Ascites disappeared. He was discharged September 5, 1940 and resumed work. On discharge laboratory data were: RBC 4.2, Hgb. $93 \%$, bromsulfalein $24 \%$, icteric index 7, serum albumin 3.8, globulin 3.7. He was seen January 
11, 1941, 10 months after entry. There was no change. He felt well.

Case 33. A 46-year-old American waitress entered the hospital February 26, 1940, because of abdominal swelling for 3 months. An accurate history was not obtainable. She had had a salpingectomy 15 years previously and pneumonia 4 years previously. She gave a history of chronic alcoholism and poor diet (no meat or dairy foods). She was admitted with delirium tremens. Chief findings were: disoriented, confused, undernourished woman; dermatitis, vascular "spiders", jaundice, glossitis, palpable liver, ascites, collateral veins, pigmented legs, edema, polyneuritis, perineal abscess; $\mathrm{RBC} 3.3$, $\mathrm{Hgb} .65 \%$, WBC 15,000 , albumin 2.3 , globulin 3.5 , icteric index 15 , bromsulfalein $64 \%$, Takata + , urine negative.

The patient was in a critical condition for 6 weeks with a temperature of $100^{\circ}$ to $102^{\circ} \mathrm{F}$. She was confused, incontinent of urine and feces. One abdominal tap was performed. Diuresis with loss of ascites and edema occurred after 8 weeks. Thereafter, she showed striking general improvement: incontinence subsided; she became mentally lucid; gained 20 lbs.; dermatitis, glossitis, and polyneuritis subsided; vascular "spiders" and jaundice disappeared; liver edge receded; spleen was not palpable. On discharge August 15, 1940, 6 months after entry, laboratory data were: $\mathrm{RBC} 4.3$, Hgb. $75 \%$, WBC 8,000, icteric index 5 , bromsulfalein $8 \%$, Takata negative, serum albumin 4.8, globulin 3.2. The patient was seen in O.P.D. 2 months later and there was no clinical change; she felt well.

Case 34. A 50-year-old American housewife entered the hospital March 19, 1940, because of abdominal swelling. She gave a history of chronic alcoholism and poor diet (no meat, no dairy foods). She had had repeated nose bleeds for 5 years and intermittent abdominal distress for 4 years; she had known of her hypertension for 2 years. In the year before her admission to the hospital her weight had fallen from 145 to 121 . Five months before (October 1939) she had been hospitalized for 1 month. Chief findings were: delirium tremens, jaundice, moderate ascites, edema, palpable liver and spleen, collateral veins; icteric index 20 , Kline $2+$, B.P. 166/88. One month before she had been hospitalized with similar findings. A peritoneoscopy, with removal of about 1 liter of fluid, showed "hob-nail" liver. She received injections of thiamin chloride and ascorbic acid, glucose infusions and mercurial diuretics. She was transferred to Research Service March 19, 1940. Chief findings were: Pale, nervous, irritable woman; mentally cloudy, coarse tremor of hands, lateral nystagmus, many vascular "spiders" on face and thorax, subicteric sclerae, glossitis, bleeding gums, palpable liver and spleen, collateral veins, moderate ascites. B.P. varied from 130/80 to $190 / 100$; venous pressure 85 , circulation time $9 \mathrm{sec}-$ onds. There was no peripheral edema and no cardiac enlargement. Laboratory data were: RBC 3.5, Hgb. $63 \%$, WBC 8,500 , albumin 2.8 , globulin 4.0 , icteric index 15 , Takata + , bromsulfalein $68 \%$.

The patient showed a rapid gain in strength and weight, with loss of tremor. Ascites disappeared in 2 months. She became mentally clear and was discharged on June 29, 1940, 3 months after entry. Laboratory data were: RBC 4.4, Hgb. $89 \%$, WBC 8,700, albumin 3.9, globulin 4.2, Takata + , icteric index 5 , bromsulfalein $50 \%$. She was seen in O.P.D. 6 months later and felt entirely well; there was no clinical change.

Case 36. A 40-year-old Porto Rican entered the hospital May 1, 1940, because of jaundice and G.I. distress. He gave a history of alcoholism and poor diet. $\mathrm{He}$ had had migratory polyarthritis for 15 years, epistaxes for 10 years, anorexia, nausea and vomiting for 2 years. He had had jaundice for 2 months, followed by onset of ascites. He was hospitalized September 6, 1939, and received mercupurin injections and vitamin supplements. Diuresis with loss of ascites occurred in 5 weeks. His weight 10 years previously had been 172 ; 1 year previously 155; before diuresis 140 ; after diuresis $120 \mathrm{lbs}$. He was discharged October 23, 1939, and was seen in O.P.D. 1 week later. Chief findings were: Vascular "spiders", pigmentation, slight jaundice, glossitis, collateral veins, palpable liver, polyneuritis; $\mathrm{RBC} 3.5, \mathrm{Hgb}$. $78 \%$, WBC 4,100, albumin 3.9, globulin 4.6 , icteric index 12.5. Takata + , bromsulfalein $40 \%$. There was no splenomegaly and ascites was doubtful.

The patient was seen periodically in O.P.D. and was maintained on vitamin therapy. He gained $30 \mathrm{lbs}$. in 7 months and gained in strength. There was no ascites. He reentered the hospital May 1, 1940, with fever, nausea, vomiting, and diarrhea of 3 weeks' duration. In addition to previous findings, he had jaundice (icteric index 25) and a palpable spleen. His temperature was 100 to $102^{\circ}$ $F$. for 5 days. The jaundice cleared. He was discharged in 3 weeks. There was no essential change in blood counts or proteins. He resumed work May 20, 1940. On October 1, 1940, 1 year after his first hospital entry, there was no clinical change.

\section{Group 3}

Case 8. A 48-year-old Italian butcher entered the hospital September 16,1937, because of abdominal swelling. He gave a history of chronic alcoholism and poor diet. He had had arsphenamine therapy 3 years previously and nausea and vomiting for 1 year. He had had swelling of abdomen, legs and scrotum for 5 months, with occasional diarrhea and melena. Three abdominal taps had been performed the previous month in another hospital from which he was transferred to Research Service. Chief findings were: Emaciation, glossitis, right hydrothorax, ascites, edema, palpable liver and spleen, vascular "spiders", RBC 4.0, Hgb. $68 \%$, WBC 3,000, serum albumin 2.4, globulin 2.7, Takata + , Kahn + , bromsulfalein $40 \%$, icteric index 4 , venous pressure $65 \mathrm{~mm}$.

Two abdominal taps were performed in the first 2 weeks. The patient failed rapidly; became incontinent of urine and feces and ran a terminal fever (Temperature $102^{\circ} \mathrm{F}$.). He died October 11, 1937, 1 month after entry. Autopsy showed portal cirrhosis; purulent pericarditis (pneumococcus type 6); phlegmonous enteritis and colitis. 
Case 13. A 55-year-old American housewife entered the hospital April 3,1937, because of abdominal swelling. She gave a history of chronic alcoholism and poor diet. She had had nausea, vomiting and weakness for six months, with occasional diarrhea. Four months before admission she developed jaundice, followed by swelling of abdomen and legs, and increasing mental confusion. She entered another hospital and was transferred to Research Service after three abdominal taps had been performed. Chief findings were: Emaciated, euphoric woman; lateral nystagmus, atrophy of tongue, ascites, dry skin, edema, wrist and foot drop, absent knee and ankle jerks, palpable spleen; RBC 3.3, Hgb. $61 \%$, WBC 10,000 , serum albumin 2.2 , globulin 3.2 , bromsulfalein $40 \%$, Takata + , icteric index 3 . Liver could not be felt.

There was progressive failure, with abdominal taps at biweekly intervals. The patient died June 14, 1937, 2 months after entry. Autopsy showed portal cirrhosis of liver.

Case 11. A 58-year-old Irish longshoreman entered the hospital because of abdominal swelling. He had had arsphenamine therapy 27 years previously; malaria 25 years previously; was a chronic alcoholic; and his diet was inadequate. His best weight had been 208 . His weight on admission was 144 lbs. He had had rheumatic fever 2 years previously with carditis (fibrillation); ascites had been noted 1 year previously. One abdominal tap had been performed at another hospital. Thereafter, biweekly diuretics controlled ascites until 1 month before admission. He was transferred to Research Service. Chief findings were: Emaciated, elderly man; skin dry and scaly; legs pigmented and purpuric; teeth missing; heart slightly enlarged, slow fibrillation, rate 75 per minute; B.P. 130/75; ascites; umbilical hernia; collateral veins prominent; hemorrhoids. Liver and spleen could not be felt; no CNS changes. Laboratory data were: RBC 3.9, Hgb. $81 \%$, WBC 6,200, venous pressure 98, circulation time 15 seconds, bromsulfalein $40 \%$, Takata + , icteric index 5 , serum albumin 2.2 , globulin 4.5 , total cholesterol 238, ester 152. E.K.G. showed auricular fibrillation.

The patient failed rapidly. Three abdominal taps were performed. He died in coma, 1 month after entry. Autopsy showed portal cirrhosis, bilateral obliterative pleuritis, obliterative pericarditis, fibrous encapsulation of liver and spleen, chronic pancreatitis.

Case 19. A 57-year-old Italian laborer entered the hospital March 28, 1938, because of abdominal swelling. There was no history of jaundice or alcoholism. He had had a rapid onset of ascites 7 months previously and cramp-like lower abdominal pains for 5 months. He had had a laparotomy 2 months before admission. A "small, shrunken, nodular liver" had been found. His usual weight had been 165 ; his weight on admission was 134 lbs. Chief findings were: Emaciated, pale man; skin dry and scaly; heart and lungs normal; B.P. 115/90; prominent abdominal veins; ascites; bilateral inguinal herniae; hernia of operative wound. No vascular "spiders", liver and spleen not felt. Laboratory data were:
RBC 5.2, Hgb. 92\%, WBC 6,000, serum albumin 3.6, globulin 4.3, Takata + , bromsulfalein $28 \%$, icteric index 7, cholesterol 207.

The patient had abdominal taps every 3 weeks. His course was stationary until he had a massive hematemesis on September 9, 1938. He responded well to transfusion. Signs of pneumonia appeared on January 13, 1939, when he had a white cell count of 34,000 . Death occurred 4 days later. Autopsy showed portal cirrhosis, esophageal varices, lobular pneumonia ; organized, old portal thrombosis, fresh retrograde thrombosis of mesenteric veins.

Case 21. A 48-year-old German chef entered the hospital October 22, 1937, because of swollen abdomen. He was a chronic alcoholic. He had had salvarsan and bismuth injections 9 years previously. He had been hospitalized 2 years ago (1935) because of abdominal pain and vomiting; a large liver had been noted. He was placed on a high CHO, low protein, low fat diet; the symptoms persisted. He had occasional diarrhea. He entered another hospital 1 month previously and was transferred to Research Service after one abdominal tap. His usual weight was 175 ; his weight on admission was 155. Chief findings were: Pallor, vascular "spiders", ascites, edema, collateral veins, left hydrothorax, B.P. $145 / 88$, liver and spleen palpable. There were friction rubs over liver and spleen. The heart was not enlarged. There were no CNS changes. Laboratory data were: RBC 2.27, Hgb. 55\%, hematocrit 26, WBC 3,000, serum albumin 2.9, globulin 3.4, icteric index 5, Takata + , bromsulfalein $36 \%$, Kahn $2+$, venous pressure 30 , circulation time 10 seconds. E.K.G.'s were normal. The ascitic fluid contained $3 \%$ albumin.

The patient ran a spiking temperature from 98 to $101^{\circ} \mathrm{F}$. daily throughout his 14-month course. Cultures of blood and pleural and ascitic fluids were sterile. $\mathrm{Ab}$ dominal taps were performed at 3-week intervals for 3 months. Two transfusions of $250 \mathrm{cc}$. each were given. He had no taps for 3 months. Moderate diuresis occurred with loss of ascites. He gained in strength. Serum albumin rose from 2.2 to 3.5 grams. Thereafter, there was progressive failure for 8 months. He had recurrent ascites with weekly paracenteses; the ascitic fluid became bloody; epistaxes and hematuria appeared; there was no response to vitamin $K$ therapy; an $a b-$ dominal tap performed December 18, 1939, was grossly bloody. On December 19, 1939, laboratory data were: RBC 2.0, Hgb. 37\%, WBC 32,000, serum albumin 2.0, globulin 2.3, Takata + , bromsulfalein $>40$, icteric index 5. The patient died in shock despite a transfusion of $500 \mathrm{cc}$. blood. Autopsy showed portal cirrhosis, esophageal varices, hemoperitoneum, fibrous adhesions of pericardium, pleura, and peritoneum; encapsulation of liver and spleen by dense fibrous tissue.

\section{BIBLIOGRAPHY}

1. Tyagaraja, S., Early pathological changes in the liver in the tropics with special reference to cirrhosis. Ceylon J. Sc., Sect. D, Med. Sc. (pt. 3), 1937, 4, 119. 
2. Yang, C. S., Cirrhosis of the liver. Report of 84 cases. Nat. M. J. China, 1928, 14, 195.

3. Wang, C. F., Cirrhosis of the liver. I. Etiology, symptomatology, liver function tests, and gastric juice findings. Chinese M. J., 1936, 50, 891.

4. Yenikomshian, H. A., Non-alcoholic cirrhosis of the liver in the Lebanon and Syria. J. A. M. A., 1934, 103, 660.

5. Sutherland, D. W., The pathology of cirrhosis of the liver. Indian M. Gaz., 1905, 40, 121.

6. Tirumurti, T. S., and Radhakrishna Rao, M. V., The rôle of malaria in the causation of cirrhosis of the liver. Indian J. M. Research, 1936, 24, 149.

7. Strauss, M. B., The etiology of "alcoholic" polyneuritis. Am. J. M. Sc., 1935, 189, 378.

8. Spies, T. D., and De Wolf, H. F., Observations on the etiological relationship of severe alcoholism to pellagra. Am. J. M. Sc., 1933, 186, 521.

9. Davis, N. C., and Whipple, G. H., The influence of fasting and various diets on the liver injury effected by chloroform anesthesia. Arch. Int. Med., 1919, 23, 612.

10. Sebrell, W. H., "Yellow liver" of dogs (fatty infiltration) associated with deficient diets. U. S. Nat. Inst. Health Bull., 1933, No. 162, 23.

11. Rhoads, C. P., and Miller, D. K., Hepatic dysfunction in dogs fed diets causative of black-tongue. J. Exper. Med., 1938, 67, 463.

12. György, P., and Goldblatt, H., Hepatic injury on a nutritional basis in rats. J. Exper. Med., 1939, 70, 185.

13. Rich, A. R., and Hamilton, J. D., The experimental production of cirrhosis of the liver by means of a deficient diet. Bull. Johns Hopkins Hosp., 1940, 66, 185.

14. Chaikoff, I. L., and Connor, C. L., Production of cirrhosis of the liver of the normal dog by high fat diets. Proc. Soc. Exper. Biol. and Med., 1940, 43, 638.

15. Earle, D. P., Jr., and Victor, J., Cirrhosis of the liver caused by excess dietary cystine. J. Exper. Med., 1941, 73, 161.

16. Von Glahn, W. C., and Flinn, F. B., The effect of yeast on the incidence of cirrhosis produced by lead arsenate. Am. J. Path., 1939, 15, 771.

17. Kensler, C. J., and others, Partial protection of rats by riboflavin with casein against liver cancer caused by Dimethylaminoazobenzene. Science, 1941, 93, 308.

18. Goldschmidt, S., Vars, H. M., and Ravdin, I. S., The influence of the foodstuffs upon the susceptibility of the liver to injury by chloroform and the probable mechanism of their action. J. Clin. Invest., 1939, 18, 277.

19. Miller, L. L., and Whipple, G. H., Chloroform liver injury increases as protein stores decrease. Am. J. M. Sc., 1940, 199, 204.

20. Smith, M. I., The influence of diet on the chronic toxicity of selenium. U. S. Pub. Health Rep., 1939, 54, 1441.
21. Patek, A. J., Jr., Treatment of alcoholic cirrhosis of the liver with high vitamin therapy. Proc. Soc. Exper. Biol. and Med., 1937, 37, 329.

22. Ratnoff, O., and Patek, A. J., Jr., The natural history of cirrhosis of the liver. A statistical analysis of 386 cases. (To be published.)

23. O'Leary, P. A., Greene, C. H., and Rowntree, L. G., Diseases of the liver: VIII. The various types of syphilis of the liver with reference to tests for hepatic function. Arch. Int. Med., 1929, 44, 155.

24. Baldridge, C. W., The relationship between antisyphilitic treatment and toxic cirrhosis. Am. J. M. Sc., 1934, 188, 685.

25. Schumacher, G. A., Causative factors in the production of Laennec's cirrhosis with special reference to syphilis. Am. J. M. Sc., 1937, 194, 693.

26. Wayburn, E., and Guerard, C. R., Relation between multiple peripheral neuropathy and cirrhosis of the liver. Arch. Int. Med., 1940, 66, 161.

27. Alexander, L., Wernicke's disease. Identity of lesions produced experimentally by $B_{1}$ avitaminosis in pigeons with hemorrhagic polioencephalitis occurring in chronic alcoholism in man. Am. J. Path., 1940, 16, 61.

28. Cleckley, H. M., Sydenstricker, V. P., and Geeslin, L. E., Nicotinic acid in treatment of atypical psychotic states. J. A. M. A., 1939, 112, 2107.

29. Pohle, F. J., and Stewart, J. K., Observations on the plasma prothrombin and the effects of vitamin $\mathrm{K}$ in patients with liver or biliary tract disease. J. Clin. Invest., 1940, 19, 365.

30. Patek, A. J., Jr., Post, J., and Victor, J. C., The vascular "spider" associated with cirrhosis of the liver. Am. J. M. Sc., 1940, 200, 341.

31. Post, J., and Patek, A. J., Jr., Serum proteins in cirrhosis of the liver. Arch. Int. Med. (In press.)

32. Hanger, F. M., and Patek, A. J., Jr., The cephalin flocculation test in cirrhosis of the liver. Am. J. M. Sc., 1941, 202, 48.

33. Patterson, H. S., Ascites in cirrhosis of the liver cured by repeated tappings. Am. J. M. Sc., 1909, 137, 699.

34. Chapman, C. B., Snell, A. M., and Rowntree, L. G., Decompensated portal cirrhosis. Report of one hundred and twelve cases. J. A. M. A., 1931, 97, 237.

35. Rolleston, H. D., and McNee, J. W., Diseases of the Liver, Gall Bladder, and Bile Ducts. Macmillan, London, 1929, 3rd Ed.

36. Henrikson, E. C., Cirrhosis of the liver. Arch. Surg., 1936, 32, 413.

37. Eppinger, H., Die Leberkrankheiten. Springer, Wien, 1937.

38. Manaranche, J. G., Contribution á L'Etude du pronostic des cirrhoses. (Paris thesis.) Le François, Paris, 1931.

39. Bloomfield, A. L., The natural history of chronic hepatitis (cirrhosis of the liver). Am. J. M. Sc., 1938, 195, 429. 
40. Jones, C. M., and Eaton, F. B., The prognostic significance of a spontaneous diuresis in acute or subacute disease of the liver. New England J. Med., 1935, 213, 907.

41. Mouras, J., De la curabilité de la cirrhose alcoolique en particulier par l'opothérapie hépatique. (Paris thesis.) Paris, 1901.

42. Gyr, E., Un cas de cirrhose avec ascite traité par l'opothérapie. Rev. Méd. de la Suisse Rom., 1908, 28, 413.

43. Wallich, R., Contribution a l'étude des rétentions aqueses de l'organisme; recherches sur les albumines de sérum sanguin au cours des cirrhoses du foie. (Paris thesis.) Jouve, Paris, 1930.

44. Goodhart, R., and Jolliffe, N., Effects of vitamin ( $\left.B_{1}\right)$ therapy on the polyneuritis of alcohol addicts. J. A. M. A., 1938, 110, 414.
45. Snell, A. M., Recent advances in the treatment of hepatic disease. Minnesota Med., 1940, 23, 551.

46. Cates, H. B., Relation of liver function to cirrhosis of liver and to alcoholism. Arch. Int. Med., 1941, 67, 383.

47. McCartney, J. S., Latent portal cirrhosis of the liver. Arch. Path., 1933, 16, 817.

48. Denton, J., Pathology of pellagra. Am. J. Trop. Dis., 1925, 5, 173.

49. Harris, H. F., Pellagra. Macmillan, New York, 1919, p. 163.

50. Patek, A. J., Jr., and Haig, C., The occurrence of abnormal dark adaption and its relation to vitamin A metabolism in patients witn cirrhosis of the liver. J. Clin. Invest., 1939, 18, 609.

51. Brinkhous, K. M., Plasma prothrombin; vitamin K. Medicine, 1940, 19, 329. 